\title{
DUCTILE TEARING STABILITY ANALYSIS OF A SHIP STRUCTURE CONTAINING A CRACK ARRESTER STRAKE
}

Reference

NBS

PUBLICATIONS
A. V. Clark, Jr.
D. T. Read

National Bureau of Standards U.S. Department of Commerce Boulder, Colorado 80303

January 1986

$-Q C$ 100 .456 



\section{DUCTILE TEARING STABILITY ANALYSIS OF A SHIP STRUCTURE CONTAINING A CRACK ARRESTER STRAKE}
A. V. Clark, Jr.
D. T. Read

Fracture and Deformation Division

Institute for Materials Science and Engineering

National Bureau of Standards

Boulder, Colorado 80303

January 1986

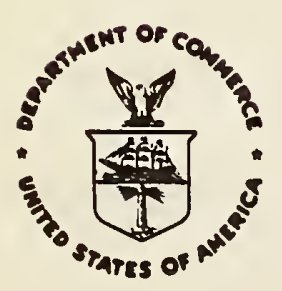

U.S. DEPARTMENT OF COMMERCE, Malcolm Baldrige, Secretary 



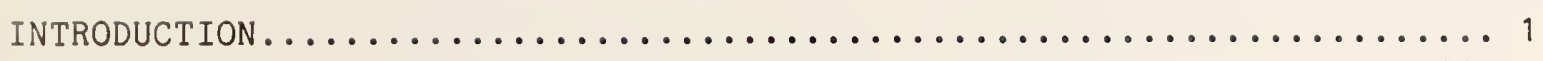

Overview of the Interaction Between Crack Arrester Strakes

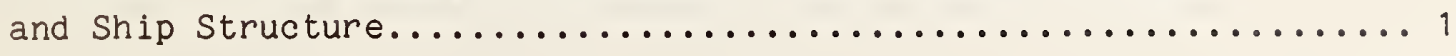

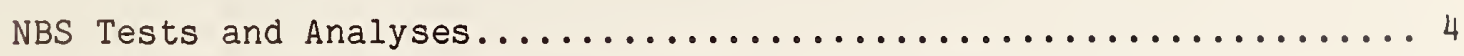

Problem Areas in Crack Reinitiation/Ductile Tearing........... 5

CRACK ARRESTER DESIGN METHODOLOGY.................... 6

DUCTILE MATERIALS CHARACTERIZATION.....................

Ductile Tearing Instability.........................

Generalization of Stability Criterion................... 8

Relation Between $\mathrm{dP} / \mathrm{d} \delta, \mathrm{da} / \mathrm{d} \delta$, and $\mathrm{T}_{\operatorname{mat}} \ldots \ldots \ldots \ldots \ldots \ldots \ldots \ldots \ldots \ldots$

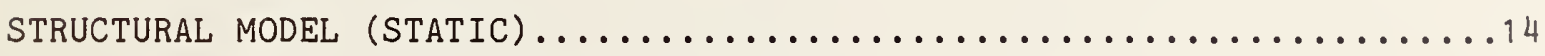

Modeling the Ship Structure With springs.....................

Simplified Model for Quasistatic Stability Criterion............16

DYNAMIC RELOADING FOLLOWING ARREST $\ldots \ldots \ldots \ldots \ldots \ldots \ldots \ldots \ldots \ldots$

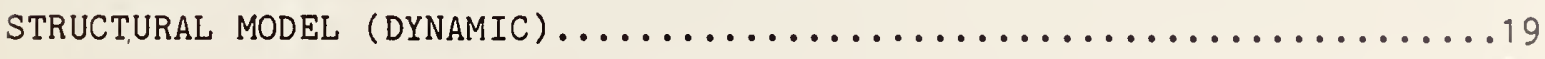

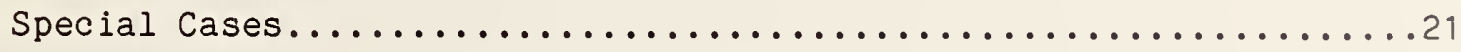

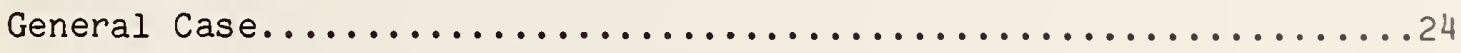

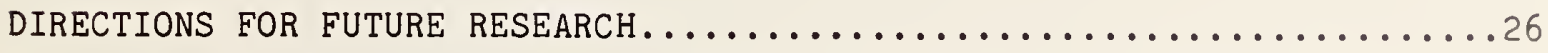

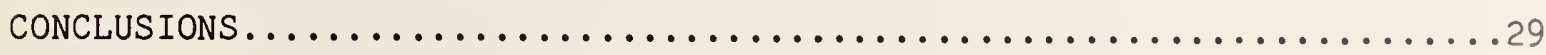

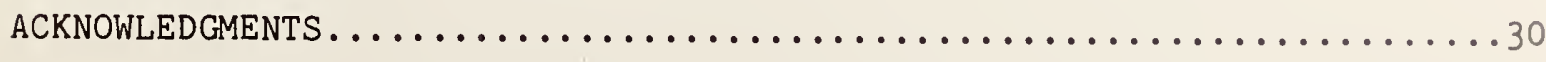

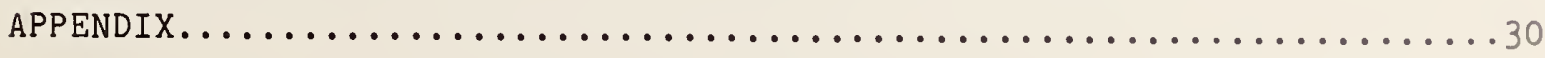

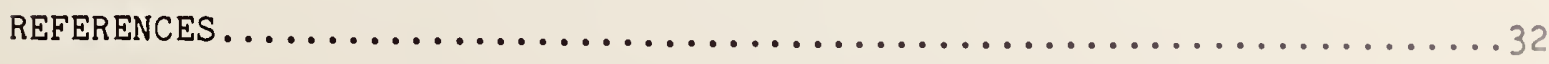


. 


\title{
DUCTILE TEARING STABILITY ANALYSIS OF A SHIP STRUCTURE CONTAINING A CRACK ARRESTER STRAKE
}

\author{
A. V. Clark, Jr., and D. T. Read \\ Fracture and Deformation Division \\ National Bureau of Standards \\ Boulder, Colorado 80303
}

An analysis is presented for a structure made up of a crack arrester plate embedded in a ship structure. The crack arrester material is specified by its crack arrest temperature, its strength, and its tearing

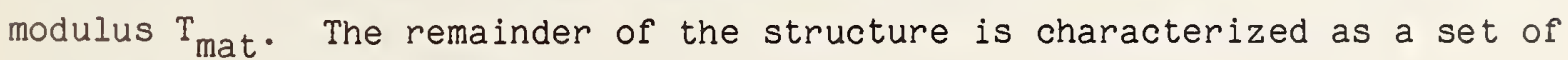
springs and lumped masses.

A stability condition is derived which states that the loaddisplacement curve of the structure as a whole must increase monotonically. An approximate quasistatic stability criterion sets a minimum material tearing modulus value that depends on the structural stiffness. Higher stiffness promotes effective crack arrest. A calculation including dynamic effects requires forward integration of a set of differential equations describing the fracture process and the motion of the structure. Repeating such a calculation for different values of crack arrester widths could indicate the minimum width needed for a successful (stable) crack arrest.

Key words: arrester strakes, crack arresters, ductile fracture, ductile tearing instability, structural instability.

\section{INTRODUCTION}

Overview of the Interaction Between Crack Arrester Strakes and Ship Structure

Crack arrester strakes are the last line of defense in preventing catastrophic failure of surface ships due to crack propagation. For reasons of economy, current practice for many types of ships is to fabricate the bulk of the ship structure (hull, decks, etc.) from materials 
which can be thought of as brittle (low fracture toughness). To prevent total failure of the ship structure due to crack propagation, arrester strakes are welded into the hull and deck at critical locations. Current practice is to install arrester strakes at the gunwale and at the turn of the bilge [1], thus dividing the ship into four sections. It has been recommended that at least two additional arresters be placed in ships with a beam of $37 \mathrm{~m}(120 \mathrm{ft})$ or less and three additional arresters for ships having a greater beam [2].

For simplicity, the ship structure can be idealized as a hull girder in the shape of a box beam with varying section modulus (varying stiffness and area moment of inertia). The hull girder is subjected to a variety of in-service loads. However, the primary loads are those due to wave action [1]. The primary hull girder loads result from the differences between the dead load of the ship and buoyancy forces. The ship is assumed to be balanced on a standard wave with the crest centered amidships (hogging) or the trough centered amidships (sagging). Either of those conditions results in a bending moment applied to the ship. The bending moment is used to calculate the longitudinal bending, or primary, stresses, once the hull girder section modulus is known.

The primary stresses typically have a frequency on the order of a few cycles/second, since they are associated with sea states. These stresses may, under unfavorable conditions, cause crack propagation. Even if some other dynamic loading (accident, explosion, etc.) initiates crack propagation, the primary stresses still act as crack driving forces, since they are applied quasistatically during the crack propagation event.

As the crack propagates through a structural element (deck, hull, etc.) the compliance of that element rapidly increases. Because the primary stresses are quasistatically applied, the mass of the element begins to accelerate as the compliance increases. When the crack is arrested, the inertia of the mass will cause a dynamic load to be applied to the arrester strake. The mass of the cracked structural element has been accelerating as the compliance increases; to decelerate the mass will require a force to be exerted by the uncracked portion of the structure. From the principle of action and reaction (Newton's third law), an inertial force will therefore be exerted by the mass on the uncracked 
structure, and in particular, on the uncracked ligament of the arrester strake.

The problem of crack arrester design is twofold. First, a suitable arrester material must be chosen. Second, the physical dimensions (length, width, thickness) of the arrester must be determined.

In order to certify a material as suitable for use in crack arresters, it is necessary to show that the material has enough fracture toughness to arrest a crack for values of stress intensity corresponding to the crackdriving force in an actual vessel. Because the crack arrest toughness changes rapidly over a small temperature interval, this requirement implies a requirement on the ductile-brittle transition temperature. The material must also have a high tearing modulus so that it will prevent failure of the arrester by ductile tearing instability in an arrestreinitiation event.

We will show later that the required value of tearing modulus for stability depends upon the stiffness of certain elements of the ship structure.

Current practice is to place crack arresters along the amidships $3 / 5$ of the vessel [1]; this criterion determines the arrester length. For an arrester in the form of a plate, the thickness should be chosen to match the thickness of the deck (or hull) in which the arrester is embedded; otherwise, stress concentrations will occur due to discontinuity in deck thickness. (It is assumed that the elastic properties of the crack arrester and the deck and hull plating are the same). Consequently, the only remaining design variable is the arrester width.

Obviously, the width must be such that the arrester can stop a running crack; i.e., $w>a_{0}$ where $w=$ arrester width, $a_{0}=$ crack length at arrest. This inequality is merely a lower bound an arrester width, however. Because of dynamic reloading of the remaining ligament, the possibility of reinitiation and consequent failure by ductile tearing exists; the arrester width must be large enough to prevent failure by ductile tearing instability. 
NBS Tests and Analyses

A previous report documented a test methodology developed at NBS in support of efforts for certifying new materials for use in crack arresters [3]. A novel specimen design was developed which allowed a crack to run through a brittle material and then encounter a step in fracture toughness. This simulates (locally) the situation in an actual vessel where a crack runs through brittle plating in the deck (or hull) and is arrested by a tough ductile arrester strake.

Furthermore, the NBS tests were designed to simulate the dynamic reloading which would be expected to occur in a vessel upon crack arrest. This was accomplished by using a spring-loaded double-cantilever beam (DCB) as the specimen design [3]; see figure 1. This configuration allows large crack lengths to be achieved using relatively low loads. The spring in the load train prevents large load drop as the crack runs (and specimen compliance increases). It also provides a means for dynamic reloading of the remaining ligament after arrest has occurred. This simulates, in a qualitative sense, dynamic reloading that would be experienced by an arrester strake in service.

In [3], the response of the DCB specimen was calculated during the crack run event on the assumption of negligible ductility. After arrest, and upon reloading, extensive plastic deformation occurs; the strain rates and crack velocity are now much lower. It was assumed that fracture parameters such as the $J$-integral and the tearing modulus are still valid during the reinitiation/ductile tearing event.

Two methods were used in [3] to calculate $J$. In the first method, a quasistatic analysis of the DCB specimen was performed assuming a plastic hinge had developed upon crack reinitiation. The J-integral was split into an elastic and a plastic part:

$$
J=J_{e}+J_{p}
$$

where $J_{e}=K^{2} / E, K$ is the stress intensity factor and $E$ is Young's modulus. Both $J_{e}$ and $J_{p}$ depend upon the crack length, $a(t)$, in a complicated fashion; it is necessary to know $a(t)$ from test records to calculate $J$ with this approach. 
The second method uses a lumped-mass viscoelastic-plastic model to account for the mass and stiffness of the specimen plus load train; see figure 2. It also accounts for elevation of the yield stress due to strainrate effects. The effect of crack propagation is modelled by a sliding frictional device (shown in fig. 2 as $P_{S}$ ) which slides freely when the load in the specimen exceeds the limit load, $P_{L}$, and is rigid when the load is less than $P_{L}$. The limit load is also a function of the crack length.

In [3], the limit load was calculated on the assumption that $a(t)=$ $a_{0}$; i.e., the crack length was assumed to be the same value during tearing as at arrest. (Obviously, the measured value of $a(t)$ could be input to the model of [3] if desired.) Note that the model represents (qualitatively) the situation in a ship. The mass $M$ and stiffness $k$ represent the effective mass and stiffness of the structure external to the arrester, which has its own mass $M_{S}$ and stiffness $k_{S}$.

The motion of the lumped-mass model was calculated and then used to determine a dynamic J-integral and applied tearing modulus. The resulting values of $\mathrm{J}$ were believed to be too large [3], leading to questions of the validity of this model.

Problem Areas in Crack Reinitiation/Ductile Tearing

From the discussion, it is seen that several problems exist with the approaches taken to model the crack reinitiation/ductile tearing event:

(1) The quasistatic approach neglects dynamic effects as a possible crack-driving force.

(2) The lumped-mass model qualitatively models the effect of the ship structure by a single mass and spring in series with the arrester. A method is needed to determine the actual values of the effective mass and stiffness of the ship structure.

(3) Both models require the crack length to be input as a function of time. There is no way of calculating $a(t)$.

(4) Both models have $J(t)$ as output. Dynamic $J$ has not yet been shown to be a valid fracture parameter [3]. 
This report summarizes recent research which attempts to overcome the four problems listed above. To deal with (1) and (2), the interaction between the arrester and the ship structure is considered. There must be continuity of displacements and tractions at the interface between arrester and structure. This fact is used to show how the effect of the inertia and stiffness of the structural elements of the ship (e.g. hull, deck) should be incorporated into a simple model consisting of masses and springs.

To solve problems (3) and (4), a tearing modulus approach is used. It is assumed that the material's tearing modulus, $T_{\text {mat }}(a)$, is known. Under certain conditions (explored later in this report), knowledge of the tearing modulus, coupled with a calculation of the response of the system of masses and springs representing arrester and ship, allows a calculation of $a(t)$ to be made. Obviously, if $a(t)>w$ at any time, the arrester has failed. What is desired in the arrester design is that $a(t)<w$ when the crack driving force vanishes (or becomes constant).

\section{CRACK ARRESTER DESIGN METHODOLOGY}

We assume that a material has been chosen which will arrest a running crack. The material must have sufficient fracture toughness to force a brittle-to-ductile fracture mode transition in order to arrest the crack at the minimum service temperature. It must also be sufficiently tough to arrest a crack which may be reinitiated upon dynamic reloading of the uncracked arrester ligament.

As mentioned previously, the design task is to size the arrester. In particular, the width of the arrester must be chosen so that any reinitiated crack will be arrested inside the arrester. Failure to arrest a reinitiated crack will result in the crack propagating from the arrester into brittle regions of the ship structure with potentially catastrophic consequences.

A procedure for crack arrester design is shown in figure 3. The designer chooses an initial crack arrester width, w, for the arrester material. The material should be characterized by its tearing modulus, and its load-displacement curve during tearing. 
A simple dynamic model for the crack run-arrest event has been previously developed by NBS [3]. The outputs of the model are crack opening displacement, $\delta$, and its time derivative, $\dot{\delta}$ (dots over a quantity will denote time derivatives in this paper). This model works reasonably well for fracture specimens which are double cantilever beams. It is assumed in this report that similar calculations have been done for the ship structure to estimate $\delta$ at arrest ( $\dot{\delta}=0$ at arrest by definition). The arrest value of $\delta$ becomes an initial value for the dynamic ductile tearing calculations.

The structural model referred to in figure 3 pertains to the actual ship structure in which the arrester is embedded. It should include the effects of the inertia and stiffness of the hull and deck, since these structural members interact with the arrester. The internal friction (damping) of these structural elements must also be included.

Using all the above inputs, the dynamic tearing model calculates crack length, $a(t)$ and $C O D, \delta$, upon reinitiation. If $\delta$ and a are bounded (in particular, if $w>a)$, then the system is stable; i.e., the arrester has stopped the crack. In this case, the design is adequate. If the system is unstable $(w<a)$, then the arrester width $w$ must be increased (or a new arrester material chosen). The process described above is then repeated until a stable design is found.

In this report, we will develop a structural model for the shipstructure-crack arrester interaction. We will develop the dynamic tearing model, and show how tearing instability is governed by dynamic crack driving forces, material tearing modulus, and structural stiffness.

\section{DUCTILE MATERIALS CHARACTERIZATION}

\section{Ductile Tearing Instability}

The simplest case of ductile tearing instability, that of a fracture specimen in series or parallel with a spring, has been considered by Ernst [4], and Kaiser and Carlsson [5]. By requiring that the total load carried be montonically increasing (specimen and spring in parallel), Ernst derived the stability criterion 
where $P=$ load carried by specimen and $K=$ spring stiffness. For the specimen and spring in series Ernst found that the stability criterion (1) could be derived by requiring that the total displacement be monotonically increasing under load.

In this section, we generalize these results to any combination of springs in series and/or parallel with the specimen. We do this by showing that the stability criterion can be derived from a fundamental principle, conservation of energy.

We note that the instability criterion (1) only holds for the case of quasistatic loading. In fact, Ernst [4] points out that eq (1) can be used to predict only the onset of instability, and not the end of instability; to predict the latter, inertial effects must be accounted for. In fact, it is the inclusion of these inertial terms that lead us to the formulation of our dynamic model.

Generalization of Stability Criterion

For simplicity, we begin with the case of a fracture specimen in series with a linear spring. This system is subjected to an applied load, $P_{e}$; see figure 4.

For a quasistatically applied load, the increment of external work applied $\left(W_{e}\right)$ to the system is equal to the increment of work ( $W_{\text {int }}$ ) represented by the area under the specimen's $P-\delta$ record. The latter work actually involves three terms: (1) elastic strain energy, (2) plastic work, (3) energy to create new surface as the crack propagates in the specimen. Obviously, the last two terms are irreversible. Energy conservation requires that

$$
\Delta\left(w_{e}-w_{\text {int }}\right)=0
$$

where $\Delta$ denotes a small increment.

For simplicity, we assume that the effect of bending in the specimen can be neglected due to constraint by the surrounding structure. Also, we assume the arrester material is sufficiently tough so that $a_{0}<<$. 
Then the crack opening displacement $\delta$ is approximately the same as the crack mouth opening displacement; i.e.e, there is no rotation of the specimen.

For a monotonic increase in $\delta$ (no elastic unloading/reloading), the area under the $\mathrm{P}-\delta$ curve is path independent; consequently, the work done on the specimen $\left(W_{S}\right)$ is

$$
\mathrm{W}_{\mathrm{S}}=\int_{0}^{\delta} \mathrm{P}(\delta) \mathrm{d} \delta
$$

The total work $W_{\text {int }}$ done on specimen and spring is just $W_{S}$ plus the strain energy $k(U-\delta)^{2} / 2$ stored in the spring where $U$ is the displacement of one terminal of the spring. The external work $W_{e}$ is just $P_{e} U$. Consequently,

(2) gives

$$
\Delta\left(W_{e}-W_{\text {int }}\right)=\frac{\partial\left(W_{e}-W_{i n t}\right)}{\partial U} \Delta U+\frac{\partial\left(W_{e}-W_{\text {int }}\right)}{\partial \delta} \Delta \delta=0
$$

Since $\Delta u$ and $\Delta \delta$ can be varied independently, we require that

$$
\frac{\partial\left(W_{e}-W_{\text {int }}\right)}{\partial U}=0, \frac{\partial\left(W_{e}-W_{\text {int }}\right)}{\partial \delta}=0
$$

Taking the derivatives gives the two equations of equilibrium

$$
\begin{aligned}
& P_{e}=k(U-\delta) \\
& P=k(U-\delta)
\end{aligned}
$$

for the spring and specimen, respectively.

Furthermore, we note that $w_{e}$ does not depend upon $\delta$. This allows us to consider whether the energy stored in the specimen-spring system is at a maximum (unstable) or a minimum (unstable). For stability, we require that

$$
\frac{\partial W_{\text {int }}}{\partial \delta}=0
$$




$$
\frac{\partial^{2} W_{\text {int }}}{\partial \delta^{2}} \geq 0 .
$$

We note that the requirement

$$
\frac{\partial^{2} W_{\text {int }}}{\partial U^{2}} \geqq 0
$$

leads to the condition $k \geq 0$, which requires a positive spring constant. Since $W_{\text {int }}=\int P d \delta+k(U-\delta)^{2} / 2$, the stability condition (7b) requires that

$d P / d \delta+k \geq 0$

which is the same as the criterion (1) derived by Ernst.

A simple physical interpretation can be given to the stability condition. Suppose that the fracture specimen in figure 4 is an isolated crack arrester strake containing a crack. Suppose also that a point mass $M$ is placed at the terminal which connects the spring to the arrester; see figure 5. As the crack grows in the arrester, the load $P$ carried by the arrester drops $(d P<0)$. The drop in load, $d P$, would accelerate the mass to the right in figure 5. However, as the load drops in the arrester, the COD $\delta$ increases by $d \delta$, thus compressing the spring. Consequently, the spring exerts a reaction force $k d \delta$ on to the left in figure 5 . If the spring is stiff enough, it will restrain any acceleration of $M$; the condition for this restraint is just the stability condition, eq (9).

This analysis can obviously be extended to more complex situations. An example is given in the Appendix, where a fracture specimen has both a spring in series and in parallel. The example models (approximately) the quasistatic tearing of an arrester placed in the hull of a ship. It is interesting to note that for the example in the Appendix, the spring in series with the arrester controls the stability of the system, rather than the spring in parallel. 
A typical set of $\mathrm{P}-\hat{\delta}$ curves is shown in figure 6 , with initial crack length $a_{0}$ as a parameter. Obviously, as $a_{0}$ increases the maximum load carried by the specimen decreases. We are concerned with the falling portion of the curve, for which $\mathrm{dP} / \mathrm{d} \delta<0$. If the slope becomes too large (in the negative sense) as the crack advances ( $\delta$ increasing), instability may occur. Obviously, for the quasistatic case, it is necessary to choose an initial $a_{0}$ small enough that when the load is applied, $-d P / d \delta<k$.

There are (at least) two possible ways of generating $P-\delta$ curves. One is to make specimens of the appropriate geometry with different initial crack lengths, load them to failure, and measure load vs. COD during the test. Another method makes use of the material's tearing modulus, Tmat, as outlined in the next section.

Relation Between $\mathrm{dP} / \mathrm{d} \delta, \mathrm{da} / \mathrm{d} \delta$ and $\mathrm{T}_{\text {mat }}$

The material's tearing modulus, $T_{\text {mat, }}$ is a measure of resistance to ductile tearing, and is defined by [6]

$$
T_{\text {mat }}=\frac{E}{\sigma \int_{0}^{2}} \quad\left(\frac{d J_{\text {mat }}}{d a}\right) .
$$

where $\sigma_{0}$ is the flow stress.

Since $J$ is a function of both crack length a and $C O D, \delta$, we have

$$
T_{\text {mat }}=\frac{E}{\sigma_{0}^{2}}\left[\left(\frac{\partial J}{\partial a}\right)_{\delta}+\left(\frac{\partial J}{\partial \delta}\right)\left(\frac{d \delta}{d a}\right)\right]
$$

showing that the rate of crack growth, da, can be related to the increment of $C O D$, $d \delta$, if the functional form of $J$ is given, and if $T_{\text {mat }}$ is known. In like fashion the load carried by the specimen depends on $a$ and $\delta$, so that

$$
\left(\frac{d P}{d \delta}\right)_{a}=\left(\frac{\partial P}{\partial \delta}\right)_{a}+\left(\frac{\partial P}{\partial a}\right)_{\delta}\left(\frac{d a}{d \delta}\right)
$$

Solving for da/do from equation (11) and substituting into (12) glves 


$$
\frac{d P}{d \delta}=\left(\frac{\partial P}{\partial \delta}\right)+\frac{(\partial P / \partial a)(\partial J / \partial j)}{\frac{\sigma_{0}^{2} T_{\text {mat }}}{E}-\left(\frac{\partial J}{\partial a}\right)_{\delta}}
$$

Ernst [4] has pointed out that the partial derivatives appearing in eq (13) are "calibration functions", that is, they can be obtained from finite-element calculations or from specimen tests. These functions do not depend upon the material's resistance to crack growth; all the information about crack growth resistance is contained in $\mathrm{T}_{\text {mat }}$.

In the most general case, it may not be possible to obtain closed form solutions for the "calibration functions." However for some simple geometries, it is possible to do so. A simple case is that of a crack which has propagated across the deck of a ship and has been arrested by an arrester strake. For simplicity, it is assumed that the crack propagates in a symmetrical fashion, so that the deck can (locally) be approximated as a center-cracked panel (CCP) with inhomogeneous fracture resistance properties; see figure 7 .

It is assumed that the arrester strakes have arrested the crack, and that the remaining ligament is fully plastic when the load is reapplied. In this case, the load carried by the panel (deck plus embedded arrester strake) is just the limit load, $P_{L}$. For a CCP in plane strain we have [6]:

$$
P_{L}=\sigma_{0}(w-a) B
$$

where $w=$ width of deck, $\sigma_{0}=$ flow stress, $B=$ thickness. For this simple case, we have, for the slope of the load displacement curve (or stiffness) $\mathrm{dP} / \mathrm{d} \delta$,

$$
d P / d \delta=-\sigma_{O} B(d a / d \delta)
$$

Note that this stiffness has a negative value as the crack length increases. 
As pointed out by Paris et al. [6],

$$
\mathrm{d} \delta=\alpha \mathrm{dJ} / \sigma_{0}=\left(\alpha / \sigma_{0}\right)(\mathrm{dJ} / \mathrm{da}) \mathrm{da}
$$

where $\alpha$ is a constant. Combining eqs (15) and (16) gives

$$
\mathrm{dP} / \mathrm{d} \delta=-\left(\sigma_{0}^{2} \mathrm{~B} / \alpha\right)(\mathrm{dJ} / \mathrm{da})^{-1}
$$

or, using the definition $T_{\text {mat }}=\left(E / \sigma_{0}{ }^{2}\right)(\mathrm{dJ} / \mathrm{da})$,

$$
\mathrm{dP} / \mathrm{d} \delta=-\mathrm{BE} / \alpha \mathrm{T}_{\operatorname{mat}}(\mathrm{a})
$$

We note that eq (17b) is equal to the value of $\mathrm{dP} / \mathrm{d} \delta$ predicted by eq (13) for the case $P=P_{L}, \alpha=1$ and $(\partial J / \partial a)_{\delta}<<\sigma_{0}{ }^{2} T_{\text {mat }}(a) / E$. We can show that the inequality holds by the following argument:

We use the well known relation [7]

$$
J=-\int_{0}^{\delta}(\partial P / \partial a) \delta d \bar{\delta}
$$

The interval of integration can be divided into two regions: from $\bar{\delta}=0$ to $\bar{\delta}=\delta_{\mathrm{NSY}}$, and from $\bar{\delta}=\delta_{\mathrm{NSY}}$ to $\bar{\delta}=\delta$. Here $\delta_{\mathrm{NSY}}=$ value of $\delta$ at net section yield.

For $0 \leqq \bar{\delta} \leqq \delta_{N S Y}$, we are performing the integration, eq (18), in the elastic region; in this region we have $J_{e}=K^{2} / E$ where $J_{e}=$ value of $J$ in the elastic region. For a center-cracked panel [8],

$$
K^{2}=\sigma^{2} \pi a \sec (\pi a / 2 w)
$$

where $\sigma=$ remote stress. The above formula is a valid approximation for $a / w \leqq 0.9$; for larger values, it over-predicts the value of $K$. Assuming eq (19) is in its range of validity,

$$
\left(\frac{\partial J_{e}}{\partial a}\right)_{\delta}=\left(\frac{\sigma^{2} \pi}{E}\right) \sec \left(\frac{\pi a}{2 w}\right)\left[1+\left(\frac{\pi a}{2 w}\right) \tan \left(\frac{\pi a}{2 w}\right)\right]
$$


For example, if $a / w=0.9$, the right-hand side of eq (20) becomes approximately $60 \pi \sigma^{2} / E$. For this quantity to be much less than $\left(\sigma_{0}^{2 / E}\right) T_{\text {mat }}$ requires $T_{\text {mat }} \gg 100\left(\sigma / \sigma_{0}\right)^{2}$.

As an example, we consider the case of HY-80 steel. The initial tearing modulus (before tearing occurs) is about 100, dropping to about 40 after several millimeters of tearing [9]. Using the (conservative) value of $\mathrm{T}_{\text {mat }}=40$ and setting $\sigma_{0}=550 \mathrm{MPa}(80 \mathrm{ksi})$ for $\mathrm{HY}-80$, the inequality $T_{\text {mat }} \gg 100\left(\sigma / \sigma_{0}\right)^{2}$ requires that the remote stress $\sigma$ be much less than about $345 \mathrm{MPa}$ ( $50 \mathrm{ksi}$ ). This requirement is almost certainly met for the case of quasistatic loading of the deck due to hogging and sagging as the ship is loaded in bending by buoyancy forces due to wave action. Dynamic reloading may cause an increase in the remote stresses, as will be discussed subsequently.

STRUCTURAL MODEL (STATIC)

Since the arrester strake is embedded in the ship, structural interaction between the arrester and the ship structure must be accounted for. From the simplest design standpoint, the ship structure is a hull girder of varying section modulus. Regarding loads applied to the ship, "...the most important loading imposed upon a ship (is) the longitudinal bending resulting from local weight-buoyancy imbalances over the length of the ship" [1]. In addition, there are loads imposed due to ship motion in various sea states, wave slap loads, etc. For the purpose of this report, all applied loads will be treated as quasistatic. That is, they are assumed to be (approximately) constant during the crack run-arrest event, and during subsequent reinitiation and ductile tearing. The only loads assumed to act dynamically are inertial loads caused when the crack arrests. More will be said about this later in the "Dynamic Model" section.

As a first approximation to a structural model, we consider the hull girder to be a box beam, as shown in figure 8. Current practice is to place arrester strakes along the amidships $3 / 5$ length of the ship [1]. The strakes are placed at the gunwale and at the turn of the bilge, thus dividing the ship into four segments [1]. For simplicity, only the arresters at the gunwales are shown in figure 8 . 
It should be noted that even this simple approximation to the ship structure is more complex than the configuration tested in [3]. It should also be noted that this model is intended as a starting point for incorporation of more realistic interaction between strake and ship structure. It is anticipated that further refinements will be made to the model based on inputs from the NAVSEA ship structures community.

The box beam in figure 8 is subjected to longitudinal bending stresses, $\sigma$, due to the weight-buoyancy imbalances which create hogging and sagging. These are the primary stresses acting on the hull [1], and for simplicity only these will be considered in this report.

Obviously, if one is concerned with modeling all structural details, even using the box beam model would involve a fairly large computer code, with elastic-plastic elements necessary to model the arrester. Such a complicated model would be accurate, but unattractive from a design standpoint.

Modeling the Ship Structure With Springs

A simpler model can be developed by considering the arrester as a free body, with constraint forces exerted upon it by the adjacent ship structure; see figure 9. The axial stress $\sigma$ is due to the longitudinal bending stress applied at the end of the box beam (shown in fig. 8) and transmitted through the deck to the arrester. The shear stress $\tau$ applied along the interface between the deck and arrester is due to the tearing of the deck. A free body diagram of the deck shows that a shear stress $\tau$ must arise to balance the remote stress $\sigma$.

Furthermore, there will be another shear stress $\tau$ acting between the arrester and the hull. As the arrester material flows plastically along slip lines at $\pm 45^{\circ}$ to the crack axis, it tries to shear the adjacent hull material. For simplicity, we show only the component of shear stress acting along the axis of the ship. Since the slip lines are at $\pm 45^{\circ}$ to this axis, there will also be a component of shear normal to the ship's axis.

To generate the simple ship structure-crack arrester interaction model we replace the effect of the distributed stresses with concentrated forces 
applied through springs connected in series and in parallel with the arrester, as shown in figure 10 .

The springs $k_{d P}$ are (conceptually) connected to the arrester on either side of the crack through rigid, massless bars welded to the arrester. These springs represent the (concentrated) effect of the shear stress $\tau$ acting between the arrester and the deck. One terminal of the spring has displacement $\delta(C O D)$, the other has displacement $U_{p}$. The latter is the displacement of the deck along its centerline, and is due (in part) to application of force $P_{p}$. This force is the (concentrated) effect of the longitudinal bending stress $\sigma$ applied to the centerline of the deck. If the deck has width $L$ and the arrester width is $w$, then $P_{p}=\sigma(L-2 w) B$.

The displacement of the deck centerline, $U_{p}$, will be resisted by the hull girder in bending. This resistance is represented by spring $\mathrm{k}_{\mathrm{HP}}$; one terminal of $\mathrm{k}_{\mathrm{HP}}$ is connected to "ground" or a position of zero displacement. This position is the neutral axis of the hull girder as in shown in figure 9.

In like fashion, there is a force $\mathrm{P}_{\mathrm{S}}=$ owB applied to the arrester through spring $k_{d S}$. This spring represents the stiffness of the deck material in the region between the end of the arrester and the end of the hull girder (recall that the arrester is placed in the amidships $3 / 5$ of the ship [1]). The deck material in question is shown in the region marked " $A$ " in figure 8. The displacement of the material in region "A" is denoted by $U_{S}$. This displacement is also resisted by bending of the hull girder, represented by the spring $k_{H S}$ in figure 9.

The effect of the shear stress $\bar{\tau}$ acting between the arrester and the hull (shown in fig. 9) is represented by spring $k_{H}$ in figure 10 . Note that $k_{H}$ and $k_{H S}$ are both connected to "ground", which is the neutral axis of the hull.

It should also be noted that since we model the deck as a CCP, there will be symmetry about the crack axis.

Simplified Model for Quasistatic Stability Criterion

The model in figure 10 can be simplified even further by recalling that we are only interested in deriving a stability condition analogous to eq (9). Consequently, the only generalized coordinate of interest is the 
COD, $\delta$. We also can make use of the fact that, for two springs $k_{1}$ and $k_{2}$ in series, the combined spring constant $k_{T}$ is given by

$$
k_{T}=\left(1 / k_{1}+1 / k_{2}\right)^{-1}
$$

which is analogous to the case of two impedances in parallel in electrical circuit theory.

Since we are concerned with stability (as opposed to equilibrium), we can ignore applied loads $\mathrm{P}_{\mathrm{S}}$ and $\mathrm{P}_{\mathrm{p}}$. The reasoning behind this statement is as follows. Equilibrium at points having displacements $U_{p}, U_{S}$, and $\delta$ can be derived by setting $\partial W / \partial u_{p}, \partial W / \partial u_{S}$, and $\partial W / \partial \delta$ to zero, respectively; here $W=W_{e}-W_{\text {int }}$. These conditions give three equilibrium equations

$$
\begin{aligned}
& P_{p}=k_{H P} U_{p}+k_{d P}\left(U_{p}-\delta\right) \\
& P_{S}=k_{H S} U_{S}+k_{d s}\left(U_{S}-\delta\right) \\
& P=-k_{H S} \delta-k_{d S}\left(\delta-U_{S}\right)-k_{d P}\left(\delta-U_{p}\right)
\end{aligned}
$$

For stability, we require that $W_{\text {int }}$ assume a minimum, so we require that $\partial^{2} W_{\text {int }} / \partial U_{p}{ }^{2}, \partial^{2} W_{\text {int }} / \partial U_{S}^{2}$ and $\partial^{2} W_{\text {int }} / \partial \delta^{2}$ all be greater than or equal to zero. In calculating these derivatives, terms involving $P_{S}$ and $P$ will obviously vanish since applied forces are not functions of the displacements.

Consequently, we can ignore the applied forces and combine the springs $k_{\mathrm{HP}}$ and $k_{\mathrm{dP}}$ into spring $k_{\mathrm{p}}$ :

$$
k_{p}=\left[\left(1 / k_{H P}\right)+\left(1 / k_{d P}\right)\right]^{-1}
$$

Likewise, springs $k_{\mathrm{ds}}$ and $\mathrm{k}_{\mathrm{HS}}$ can be combined into $\mathrm{k}_{\mathrm{s}}$ :

$$
k_{S}^{\prime}=\left[\left(1 / k_{d S}\right)+\left(1 / k_{H S}\right)\right]^{-1}
$$

The spring $k_{S}^{\prime}$ is still in parallel with $k_{H}$, so the effective spring $k_{S}$ in series with the arrester is

$$
k_{S}=k_{S}^{\prime}+k_{H}
$$


Using the above results gives a greatly simplified model for stability calculations, as shown in figure 11. Note that the coordinates $U_{S}$ and $U_{P}$ are absent from the figure, having been essentially absorbed when the effective spring constants $\mathrm{k}_{\mathrm{S}}$ and $\mathrm{k}_{\mathrm{p}}$ were calculated. Also, the stability conditions $\partial^{2} W_{\text {int }} / \partial U_{p}{ }^{2} \geqq 0, \partial^{2} W_{\text {int }} / \partial U_{S}{ }^{2} \geqq 0$ give the trivial requirements to $k_{H P}+k_{d p} \geq 0, k_{d s}+k_{H S} \geq 0$. Therefore, no loss of information results in ignoring the coordinates $U_{p}, U_{S}$ in stability calculations.

For the model shown in figure 11 ,

$$
W_{\text {int }}=\left(k_{p}+k_{s}\right)(\delta / 2)^{2}+\int P d \delta
$$

so that the stability criterion $\partial^{2} W_{i n t} / \partial \delta^{2} \geq 0$ gives

$$
-d P / d \delta \leqq\left(k_{S}+k_{p}\right)
$$

Consequently, the structural stiffness $k_{s}+k_{p}$ must be at least as large as the absolute value of the effective tearing stiffness $\mathrm{dP} / \mathrm{d} \delta$ to ensure stability in the quasistatic case. The quasistatic case will be reached after all inertial effects associated with the crack arrest/reinitiation event have died out. To see what additional requirements are necessary we must consider the dynamic reloading of the arrester.

\section{DYNAMIC RELOADING FOLLOWING ARREST}

The model depicted in figure 10 accounts (approximately) for the static effect of the ship structure on the arrester strake. It does not account for dynamic effects.

During the crack run event, the compliance of the deck is rapidly increasing. Since the remote bending stresses due to hogging/sagging are quasistatically applied during crack propagation, the center of mass of the deck experiences an acceleration. When the arrester stops the crack, the compliance quickly reaches a final value; the stiffnesses of the deck and uncracked ligament of the arrester try to restrain the motion of the mass center. The result is an inertial force which is rapidly applied to the remaining ligament of the arrester. 
A simple model which accounts for these inertial effects is shown in figure 12. This model is the same as the static model of figure 10, except that spring $k_{d P}$ is split in two and masses, $M$, inserted. For simplicity, the total mass of the deck is divided into quarters; the inertial force associated with each quarter is applied to one of the crack faces of the arrester strakes through springs $k_{d}$. Consequently, each mass, $M$, shown in figure 12 is $1 / 4$ the total deck mass.

This division of mass assumes that only the lowest mode of vibration of the deck is excited by the crack run/arrest event. Laboratory tests on SEN and DCB specimens $[3,10]$ showed that the total measured loads and displacements during crack arrest-reinitiation events were approximated reasonably well by considering only the lowest modes. If further analysis of ship structures proves this assumption wrong, it may be necessary to perform a modal analysis and consider the effect on the arrester of the inertia associated with each normal mode on the arrester.

STRUCTURAL MODEL (DYNAMIC)

Having modeled the statics and dynamics of the hull girder and having characterized the arrester strake's ductile fracture resistance properties, it is now possible to generate a mathematical model to calculate ductile tearing. Since dynamic reloading occurs upon crack arrest/ reinitiation, the static form of energy conservation eq (5) can no longer be used. Rather, the dynamic form

$$
d / d t\left(W_{e}-T-W_{\text {int }}\right)=0
$$

must be used, where $T=$ kinetic energy.

We note that there are now four coordinates $U_{S}, U_{p}, U$, and $\delta$, where $U$ is the displacement of mass, M; see figure 12. Consequently, there w1ll be four equations of motion. However, we will show that for stability calculations, we can reduce the set to just two equations involving $U$ and $\delta$, just as we were able to reduce the static model of figure 10 to the simpler model of figure 11.

The dynamic energy conservation equation generates four equations of motion since 


$$
\Delta W=\left(\frac{d W}{d t}\right) \Delta t=\left(\frac{\partial W}{\partial U_{S}} \dot{U}_{S}+\frac{\partial W}{\partial U_{p}} \dot{U}_{p}+\frac{\partial W}{\partial U} \dot{U}+\frac{\partial W}{\partial \delta} \dot{\delta}\right) \quad \Delta t
$$

where $W=W_{e}-W_{\text {int }}-T$. Since $U_{S} \Delta t=-\Delta U_{S}$, and $\Delta U_{S}, \Delta U_{p}$, etc. can be varied independently, we have

$$
\begin{aligned}
& \frac{\partial W}{\partial U_{p}}=0=P_{p}-\left[k_{H P} U_{p}+k_{d 2}\left(U_{p}-U\right)\right] \\
& \partial W / \partial U_{S}=0=P_{S}-\left[k_{d s}\left(U_{S}-\delta\right)+k_{H S} U_{S}\right] \\
& \partial W / \partial U=0=M \ddot{U}+k_{d 2}\left(U-U_{p}\right)+k_{d 1}(U-\delta) \\
& \partial W / \partial \delta=0=P+k_{d 1}(\delta-U)+k_{d s}\left(\delta-U_{S}\right)+k_{H} \delta
\end{aligned}
$$

Considerable simplification of the static model occurred because (a) $P_{p}$ and $P_{S}$ were applied (prescribed) forces so that $d P_{S}=d P_{p}=0$; (b) springs in series having common terminals at nodes $U_{S}$ and $U_{p}$ could be combined. We use a similar approach to simplify the dynamic stability calculations. Since $d P_{p}=0$, we have from eq (31a)

$$
\mathrm{dU}_{\mathrm{p}}=\frac{\mathrm{k}_{\mathrm{d} 2} \mathrm{dU}}{\mathrm{k}_{\mathrm{HP}}+\mathrm{k}_{\mathrm{d} 2}}
$$

likewise, (31b) gives

$$
\mathrm{dU}_{\mathrm{S}}=\frac{\mathrm{k}_{\mathrm{ds}} \mathrm{d} \delta}{\mathrm{k}_{\mathrm{ds}}+\mathrm{k}_{\mathrm{HS}}}
$$

The differential forms of eqs (31c) and (31d) are just

$$
\begin{aligned}
& M \ddot{d U}+\left(k_{d 2}+k_{d 1}\right) d U-k_{d 1} d \delta-k_{d 2} d_{p}=0 \\
& d P+\left(k_{d 1}+k_{d s}+k_{H}\right) d \delta=k_{d 1} d U-k_{d s} d_{S}=0
\end{aligned}
$$

Using (24a) and (24b) gives the simpler results 


$$
\begin{aligned}
& M d \ddot{U}+\left[k_{d 1}+\frac{\left(\frac{k_{d 2} k_{H P}}{k_{d 2}+k_{H P}}\right) d U}{d}=k_{d 1} d o ̈\right. \\
& d P+\left[k_{H}+k_{d 1}+\left(\frac{k_{H S} k_{d s}}{k_{H S}+k_{d s}}\right)\right] d \delta=k_{d 1} d U .
\end{aligned}
$$

The effect of the springs $k_{H P}$ and $k_{d 2}$ (connected in parallel at $U_{p}$ ) $U_{p}$ simplifies to a single spring with stiffness $k_{d 2} k_{H P} /\left(k_{d 2}+k_{H P}\right)$. The same is true of springs $k_{H S}$ and $k_{d s}$ connected to node $U_{S}$. Consequently, we have a much simpler stability model, as shown in figure 13. The new spring constant $k_{d 3}$ is defined by

$$
k_{\mathrm{d} 3}=\frac{k_{\mathrm{HP}} k_{\mathrm{d} 2}}{k_{\mathrm{HP}}+k_{\mathrm{d} 2}}
$$

and from (25) and (26),

$$
k_{S}=k_{H}+\left(\frac{k_{H S} k_{d s}^{\prime}}{k_{H S}+k_{d s}}\right) .
$$

\section{Special Cases}

Before considering the general solution of eqs (33), it is worthwhile to consider some special cases. For the static case, $\mathrm{dU}=0$, which corresponds to the state of the system after oscillations of mass $M$ have been damped out. For this case eq (33a) gives

$$
\mathrm{dU}=\left(\mathrm{k}_{\mathrm{d} 1} /\left(\mathrm{k}_{\mathrm{d} 1}+\mathrm{k}_{\mathrm{d} 3}\right)\right) \mathrm{d} \delta \text {. }
$$

Considering a free body diagram of node $\delta$ shows that stability results if

$$
-d P<k_{S} d \delta+k_{d 1}(d \delta-d U)
$$

or, using eq (35), 


$$
-d P / d o<\left[k_{s}+\left(\frac{k_{d 1} k_{d 3}}{k_{d 1}+k_{d 3}}\right)\right] .
$$

We can give a physical interpretation to eq (37). For $\mathrm{dU}=0$, the springs $k_{\mathrm{d} 1}$ and $k_{\mathrm{d} 3}$ can be combined into spring constant $k_{\mathrm{d} 1} k_{\mathrm{d} 3} /\left(k_{\mathrm{d} 1}+k_{\mathrm{d} 3}\right)=k^{\prime} p$. This spring is in parallel with spring $k_{S}$. Hence, the combined spring constant resisting the load drop in the arrester is $k^{\prime} p+k_{S}$, so the drop in load $-d P$ is resisted by the force $\left(k_{p}^{\prime}+k_{s}\right) d \delta$. Equation (37b) states that if the spring force exceeds the load drop -dP, stability will occur.

An equivalent interpretation is that the spring stiffness $k_{s}+k_{p}^{\prime}$ must be greater than the tearing stiffness $-\mathrm{dP} / \mathrm{d} \delta$. This is merely a restatement of the stability condition (28) derived for the static case. In fact, a necessary condition for the validity of the dynamic model of figure 13 is that it gives the same quasistatic stability criterion as the model of figure 11 .

Another special case occurs when $U \neq 0$, but $d P / d \delta=$ constant. For example, [5] presents data for a center-cracked panel showing a region of the $\mathrm{P}-\delta$ plot where $\mathrm{dP} / \mathrm{d} \delta=$ constant. We note that eq (17b) gives $\mathrm{dP} / \mathrm{d} \delta=$ constant when $\mathrm{T}_{\text {mat }}(\mathrm{a})=$ constant .

Combining (33a) and (33b) gives

$$
M d \ddot{U}+\left(k_{d 3}+k_{d 1}\right) d U=\left(\frac{k_{d 1} 2}{d P / d \delta+k_{S}+k_{d 1}}\right) d U
$$

Which describes the free vibration of the system shown in figure 13 when $\mathrm{dP} / \mathrm{d} \delta=$ constant. For stability, the natural frequency of the system must be real, rather than imaginary; that is, if $U=v_{0} e^{i \omega t}$, then $\omega$ must be real. Substitution of the above form of $U$ into eq (38) gives

$$
-M \omega^{2}+\left[k_{d 3}+k_{d 1}\left(\frac{d P / d \delta+k_{s}}{d P / d \delta+k_{s}+k_{d 1}}\right)\right]=0
$$

The condition for real $\omega$ is just that the effective spring constant in braces in (39) be positive:

$$
k_{d 3}+\frac{k_{d 1}\left(d P / d \delta+k_{s}\right)}{d P / d \delta+k_{s}+k_{d 1}}>0
$$


Rearranging the above leads to the requirement

$$
\left(\frac{d P}{d \delta}+k_{S}+k_{d 1}\right)^{-1}\left(\frac{d P}{d \delta}+k_{S}+k_{p}^{\prime}\right)>0
$$

Requiring that the first term in parenthesis be $>0$ is equivalent to requiring that motion of mass $M$ be stable. An instability results when $-d P / d \delta>\left(k_{S}+k_{d 1}\right)$; the total spring force resisting motion of mass $M$ drops. This causes a change in the resonant frequency of the system and also an increase in the amplitude of oscillation of mass $M$.

However, it is obvious that this instability will end. The motion of mass $M$ will still be resisted by spring $k_{d 3}$ and (combined) spring $k_{\mathrm{S}} \mathrm{k}_{\mathrm{d} 1} /\left(\mathrm{k}_{\mathrm{S}}+\mathrm{k}_{\mathrm{d} 1}\right)$. The amplitude of oscillations will increase temporarily as tearing occurs, but will reach a final value (end of instability of mass $M$ ).

Furthermore, we note that there is a fundamental difference between motion of mass $M$ and the node having displacement $\delta$. Only if $\delta$ increases without bound will a tearing unstability of the arrester occur. This tearing unstability will not occur if the second term in eq (40b) is positive. Requiring the second term to be positive is exactly the same criterion expressed by eq (37).

Since $\mathrm{dP} / \mathrm{d} \delta$ and the tearing modulus are related through eq (17b), the stability criterion for the special cases considered here can be restated as

$$
\frac{B E}{\alpha T_{\text {mat }}(a)}<\left(k_{s}+k_{p}^{\prime}\right)
$$

where $k_{p}^{\prime}=k_{d 1} k_{d 3} /\left(k_{d 1}+k_{d 3}\right.$. Clearly, the stability criterion is $v$ iolated when $T_{\text {mat }} \rightarrow 0$. Since $T_{\text {mat }}$ is proportional to dJ/da, $T_{\text {mat }}$ will vanish when the slope of the material $J-R$ curve is zero. 


\section{General Case}

We now consider the most general case, for which $\mathrm{dP} / \mathrm{d}$ i $\neq$ constant. In this case we must solve the differential equations of motion:

$$
\begin{aligned}
& M \ddot{d U}+\left(k_{d 1}+k_{d 3}\right) d U=k_{d 1} d \dot{o} \\
& d P+\left(k_{S}+k_{d 1}\right) d \delta=k_{d 1} d U .
\end{aligned}
$$

We have three unknowns: $U, \delta$, and $P$. We can obtain a well posed problem (number of unknowns equals number of equations) if we add eqs (15) and $(17 b)$ :

$$
\begin{aligned}
& \mathrm{dP}=-\left[\mathrm{BE} / \alpha \mathrm{T}_{\text {mat }}(\mathrm{a})\right] \mathrm{d} \delta \\
& \mathrm{da}=-\mathrm{dP} /\left[\sigma_{0} \mathrm{~B}\right]=\mathrm{Ed} \delta /\left[\sigma_{0} \alpha \mathrm{T}_{\text {mat }}(\mathrm{a})\right]
\end{aligned}
$$

We see that $\mathrm{dP} / \mathrm{d} \delta \rightarrow-\infty$, and $\mathrm{da} \rightarrow+\infty$ when $\mathrm{T}_{\text {mat }}=0$; i.e., failure of the arrester occurs when the tearing modulus vanishes.

We can integrate eqs (41), (17b), and (15) to calculate all unknowns, provided that $\mathrm{T}_{\text {mat }}(\mathrm{a})$ is given, and the initial conditions $U(t=0), \dot{U}(t=0), a(t=0)$ are known. The initial conditions presumably can be obtained from crack arrest calculation such as those performed in $[3,10]$. We assume for simplicity that $\delta(t=0)$ is negligible, since the COD at arrest will be much smaller than the COD which occurs during ductile tearing, for a material with a high toughness.

Denoting the initial conditions by $U_{0}, U_{0}, a_{0}$, we have, for $t=\Delta t$ (first time increment)

$$
\begin{gathered}
M\left[\dot{U}(\Delta t)-\dot{U}_{0}\right]+\left(k_{d 1}+k_{d 3}\right)\left[U(\Delta t)-U_{0}\right] \\
=k_{d 1} \delta(\Delta t) \\
k_{S}+k_{d 1}-\frac{B E}{\alpha T_{\text {mat }}\left(a_{0}\right)}-\delta(\Delta t)=k_{d 1}\left[U(\Delta t)-U_{0}\right]
\end{gathered}
$$

where we have combined (41b) and (17b). Equations (42) can be solved for $U(\Delta t), \delta(\Delta t)$ (we use $\dot{U}(\Delta t)=\left[U(\Delta t)-U_{0}\right] / \Delta t$ ); the new crack length $a(\Delta t$ ) 


$$
a(\Delta t)=a_{0}+\frac{E \delta(\Delta t)}{\sigma_{0} \alpha T_{\operatorname{mat}}\left(a_{0}\right)}
$$

The process is then repeated for $t=2 \Delta t$ using the updated value of $\mathrm{T}_{\text {mat: }}$

$$
\begin{aligned}
& M[\dot{U}(2 \Delta t)-\dot{U}(\Delta t)]+\left[k_{d 1}+k_{d 3}\right][U(2 \Delta t)-U(\Delta t)] \\
& =k_{d 1}[\delta(2 \Delta t)-\delta(\Delta t)] \\
& {\left[k_{s}+k_{d 1}-\frac{B E}{\alpha T_{\operatorname{mat}}(a(\Delta t))}\right][\delta(2 \Delta t)-\delta(\Delta t)]} \\
& =k_{d 1}[U(2 \Delta t)-U(\Delta t)] \\
& a(2 \Delta t)=a(\Delta t)+\frac{E[\delta(2 \Delta t)-\delta(\Delta t)]}{\sigma_{0} \alpha T_{\operatorname{mat}}(a(\Delta t))}
\end{aligned}
$$

Since we are considering ductile tearing, we must require da $\geq 0$ in our calculations. From eq (15), we see that da $\geqq 0$ if $d \delta \geqq 0$, since $T_{\text {mat }}(a)$ is always greater than (or equal to) zero. However, during unloading, d $\delta$ can be negative so eqs (15) (42c), and (43c) are only valid during elasticplastic loading.

Unloading of the arrester occurs when $\ddot{d} \dot{U}$ and dU are negative; the forces associated with motion of the center of mass of the deck try to close up the crack. During unloading, eq (17b) is to be replaced by

$$
d P=k_{e}(a) d \delta
$$

where $k_{e}(a)$ is the elastic stiffness of the arrester:

$$
k_{e}(a)=B E(w-a) .
$$


Consequently, during unloading we have the set of differential equations

$$
\begin{array}{r}
M \ddot{d U}+\left(k_{d 1}+k_{d 3}\right) d U=k_{d 1} d \delta \\
\left(k_{e}(a)+k_{S}\right) d \delta=k_{d 1} d U \\
d a=0
\end{array}
$$

Proceeding in this fashion, we can calculate $\delta$ and a and see if they increase without bound, or whether they reach asymtotic values. The former case indicates instability $(\delta, a \rightarrow \infty)$ whereas the latter case corresponds to stability (provided that the final value of $a(t)$ is less than the arrester width, w).

\section{DIRECTIONS FOR FUTURE RESEARCH}

The model proposed here for dynamic ductile tearing instability is a preliminary one. There are several areas where future research is necessary to prove its validity.

First, a method must be devised to calculate the stiffnesses of the various springs in the model. A necessary first step in this direction is to obtain inputs from members of the NAVSEA structures community, especially since these will be the ultimate users of the crack arrest/reinitiation model.

If simple but reasonably accurate approximations to the ship structure can be made (such as the box beam approach used here) then methods such as finite element analysis could be used to calculate the effective spring constants. To use the box beam model (hull girder) approach requires knowledge of the elastic and geometric properties of structural elements such as hull and deck plating, plus the effect of stiffeners, bulkheads, etc.

A second area of research concerns the modelling of structural damping/internal friction, and also modelling of strain-rate effects in the arrester. These effects will cause the oscillations of the masses in the model to decay. As the model is currently configured, no damping is 
included. It may therefore be overly conservative, because damping could reduce the intertial forces that tend to reinitiate cracking.

It should be noted that the effect of damping was included in the viscoelastic lumped-mass model of [3]. This was done by incorporating a viscious damping element (dashpot) to account for strain-rate elevation effects. The damping coefficient was calculated by assuming an effective (tensile) strain rate, $\dot{\varepsilon}$, which was set equal to the ratio of the rate of change of CTOD to specimen thickness. The CTOD was calculated on the assumption of formation of a plastic hinge form a limit-load analysis. The elevation of the flow stress was assumed to be linearly related to $\dot{\varepsilon}$, and hence to the rate of change of CTOD.

This approach can be used in the current model with some modification. The current model assumes net section yield on reinitiation, but without rotation, i.e., the COD and CTOD are equal and there is no plastic hinge. Slip lines are assumed to develop, emanating from the crack tip. (Recall that the deck was modeled as a center-cracked panel with the crack tips partway through the arresters; see fig. 9). Material flows plastically along these slip bands, at $\pm 45^{\circ}$ to the crack axis. Assuming the displacement is uniform along the slip lines, the corresponding strain $\varepsilon$ is $\delta / b$, where $b$ is the remaining ligament.

Assume that flow stress elevation is given by $\sigma_{0}=\sigma_{0}^{0}+C_{1} \dot{\varepsilon}$ and if $\dot{\delta} / \delta>>\dot{b} / b$, then

$$
\sigma_{0}=\sigma_{0}^{0}+c_{1} \dot{\delta} / b
$$

We note that for a material with a high fracture toughness, the unequality $\dot{\delta} / \delta \gg \dot{b} / \mathrm{b}$ should be satisfied; a large amount of plastic deformation must occur (large $\dot{\delta} / \delta$ ), with relatively small crack advance ( $\dot{b} / \mathrm{b}$ small).

Since the load $P$ carried by the arrester equals the limit load, $P_{L}$, and since $P_{L}$ depends on the flow stress (see equation (14)), we have $P=P(\delta, \dot{\delta}, a)$. The relation between $d P$ and $d \delta$ now becomes

$$
\frac{\mathrm{dP}}{\mathrm{d} \delta}=\left(\frac{\partial \mathrm{P}}{\partial \delta}\right)+\left(\frac{\partial \mathrm{P}}{\partial \delta}\right)\left(\frac{\mathrm{d} \dot{\delta}}{\mathrm{d} \delta}\right)+\left(\frac{\partial \mathrm{P}}{\partial \mathrm{a}}\right) \quad\left(\frac{\mathrm{da}}{\mathrm{d} \delta}\right)
$$

Setting $P=B\left(\sigma_{0}{ }^{0}+c_{1} \dot{\delta} / b\right)(w-a)$ and using equation (48) gives 


$$
\mathrm{dP} / \mathrm{d} \delta=\mathrm{B}\left[\mathrm{C}_{1} \mathrm{~d} \dot{\mathrm{\delta}} / \mathrm{d} \dot{0}-\sigma 8 \mathrm{da} / \mathrm{d} \dot{0}\right]
$$

where we assume $C_{1} \dot{\delta} / b<\sigma_{0}{ }^{\circ}$. Comparing eq (49) with eq (15) we see that the effect of strain-rate elevation is to make dP dependent upon the incremental strain rate $\mathrm{d} \dot{\delta} / \mathrm{b}$.

When eq (49) is substituted into the equations of motion, eqs (33), the term $C_{1} B d \dot{\delta}$ will cause oscillations of of mass $M$ to decay. Likewise, the inclusion of structural damping should also add a term $C_{2} d \dot{U}$ to eqs (33), which also causes decay of oscillations.

A third area of further research is the integration of the eqs (43) ( for $\mathrm{da}>0$ ) and eqs $(46)(\mathrm{da}=0)$. To perform the integration for an actual structure, the values of $M$ and of the spring stiffnesses must be known.

Finally, a test of the dynamic ductile tearing model could be done by comparing predicted values of $\delta$ and a with those obtained from laboratory tests, such as those reported in [3]. We note, however, that the specimen geometry used in [3] was that of a DCB in deep bending with external spring and mass. This is not the same structural model as that treated here; namely the case of a CCP which is an element of a box beam. What is required is a reformulation of the basic ideas developed here to fit the DCB test geometry. For example, the load carried by the DCB specimen could be idealized as the limit load, $P_{L}(a)$ (assuming NSY). Then eqs (13) could be used to calculate $\mathrm{dP} / \mathrm{d} \delta$ for this geometry, using the material $\mathrm{J}-\mathrm{R}$ curve and the relation $(\partial \mathrm{J} / \partial \delta)_{\mathrm{a}}=-\mathrm{B}^{-1}(\partial \mathrm{P} / \partial \mathrm{a})_{\delta}$.

The various spring constants appropriate to the DCB test configuration have already been calculated in [3]. Inequalities corresponding to the quasistatic case, eq (37), could be derived and used to predict tearing instability. These predictions could then be compared to the test results of [3]. 
We have proposed a methodology for design of crack arrester strakes. Because of current practices, the only design variable (for a given arrester material) is the arrester width, w.

To perform the design, it is necessary to:

(a) Determine the mass and stiffnesses of structural elements (deck, hull, etc.),

(b) Calculate the displacement and velocities of masses at arrest, and

(c) Know the crack arrester material's J-R curve.

Steps (a) - (c) are to be used as inputs to the dynamic ductile tearing model; the model consists of a set of differential equations which allow calculation of $\delta, a$, and displacement of masses. In the most general case, stability occurs when $\delta$ is bounded and the final value of a is < w.

The dynamic model is based in part on a generalization of the tearing instability model of [4 and 5]. The generalization allows us to treat the cases of (a) multiple springs in series and parallel with the crack arrester, (b) dynamic reloading of the arrester ligament.

We treat the ship structure as a box beam with a CCP as one of the structural elements. A free body diagram of the box beam shows how the various structural elements interact with the arresters, which are part of the CCP.

The arrester becomes a nonlinear spring element with stiffness $\mathrm{dP} / \mathrm{d} \delta$. Catastrophic failure of the arrester always occurs when $\mathrm{dP} / \mathrm{d} \delta \rightarrow-0$, or when $\mathrm{T}_{\text {mat }} \rightarrow 0$.

In both the quasistatic case, and the case $\mathrm{dP} / \mathrm{d} \delta=$ constant, stability of the arrester will occur when

$$
-d P / d \delta<\left(k_{s}+k_{p}^{\prime}\right)
$$

The spring constant $k_{s}$ represents the combined stiffness of the deck in series with the arrester and also a portion of the hull; $k_{p}^{\prime}$ is the combined stiffness of the deck in parallel with the arrester and the remaining portion of the hull. 
Satisfaction of the inequality, eq (37), is a necessary condition, but not a sufficient condition for stability in the general dynamic case. Dynamic reloading of the arrester by acceleration of e.g. the mass of the deck must be accounted for.

The model proposed here is preliminary. Actual values of stiffnesses for realistic ship structures are needed. Once these are obtained, a computer code could be written to integrate the equations governing dynamic ductile tearing in the most general case. In the meantime, it may be worthwhile to adapt the model to test configurations (such as that of [3] and compare its stability predictions with the results of actual experiments. The resulting equations of motion would be somewhat different since the test configuration of [3] is a DCB, and the structural model developed here is for a CCP in a box beam. However, the basic ides should transfer from one type of geometry or loading system to another.

\section{ACKNOWLEDGMENTS}

This work was supported as part of the Fracture Control Technology Program under the sponsorship of Mr. Charles Zanis, Naval Sea Systems Command. The effort was directed by Mr. John P. Gudas, David Taylor Naval Ship R \& D Center, under Program Element 62761N, Task Area Sf-61-544-504.

\section{APPENDIX}

Here we consider the case of a crack which has propagated through a portion of the hull, has been arrested by an arrester strake, and has reinitiated. Treating the ship as a hull girder (or box beam), we have the situation shown in figure $A-1$. We assume for simplicity that the cracked side of the hull acts as a plate with negligible interaction with the remainder of the box beam. Because of the primary (bending) stresses applied to the hull, this plate will be subjected to a bending moment, $\bar{M}$, applied at its ends.

Recall that the arrester is assumed placed in the midship $3 / 5$ of the vessel [1]. Consequently, there will be a portion of the plate between the ends of the arrester and the ends of the plate labelled "A" in 
figure A-1. We model the stiffness of this portion of the hull by springs of stiffness $k_{\mathrm{S} 1}$ as shown in figure $\mathrm{A}-2$. The uncracked portion of the hull (1ts remaining ligament) is assumed to have stiffness $k_{p}$; this region is labelled "c". Finally, there will be an effective stiffness $k_{S}$ (associated with region "B" in figure A-2), connected between the arrester and the neutral axis of the plate in bending.

We assume that the springs are connected to a rigid member, which idealizes the effect of bulkheads in the ship. Those members rotate (rigidly) through angle $\theta$, so the external work done is $2 \mathbb{M}_{\theta}$. Assuming the deformation of the arrester (fracture specimen) is adequately represented by the COD, $\delta$, the internal work done is

$$
w_{\text {int }}=\int p d \delta+k_{s 1}\left(\delta / 2-\theta l_{1}\right)^{2}+k_{s 2}(\delta / 2)^{2}+2 k_{p}\left(\theta l_{2}\right)^{2}
$$

The springs $k_{s 1}$ and $k_{p}$ are assumed connected at distances $\ell_{1}, l_{2}$, respectively, from the neutral axis.

The equations of equilibrium can be derived from

$$
\frac{\partial\left(W_{e}-W_{\text {int }}\right)}{\partial \theta}=\frac{\partial\left(W_{e}-W_{\text {int }}\right)}{\partial \delta}=0
$$

The first of these gives

$$
\bar{M}=k_{S}\left(\delta / 2-\theta \ell_{1}\right) \ell_{1}-2\left(k_{p} \theta l_{2}\right) l_{2}
$$

which is moment equililbrium for the rigid members in figure A-2. The second of eq $(A-2)$ gives

$$
P+k_{s 1}\left(\delta / 2-\theta l_{1}\right)+k_{s 2}(\delta / 2)=0
$$

Which is equilibrium of forces applied to the terminal connecting the arrester with springs $k_{\mathrm{s} 1}, \mathrm{k}_{\mathrm{s} 2}$.

For stability, we require $\partial^{2} W_{\text {int } / \partial \theta^{2}} \geqq 0, \partial^{2} W_{\text {int }} / \partial \delta^{2} \geq 0$. The first inequality gives

$$
k_{s 1} l_{1}^{2}+k_{s 2} l_{2}^{2} \geqq 0
$$


which is automatically satisfied. The second inequality gives

$$
d P / d o ̂+1 / 2\left(k_{s 1}+k_{s 2}\right)>0 \text {. }
$$

Consequently, the combined stiffness $\left(k_{s 1}+k_{s 2}\right)$ of the springs $k_{s 1}$ and $k_{s 2}$ in parallel must be larger than the tearing stiffness $-2 \mathrm{dP} / \mathrm{d} \delta$ of the specimen during ductile tearing (reinitiation in tearing mode).

Note that the uncracked portion of the hull does not contribute to the stability of the arrester in ductile tearing for the case considered here; the stiffness $k_{p}$ does not appear in stability criterion, eq $(A-4 b)$. However, the crack length will decrease the value of $k_{s 2}$, so clearly the problem of ductile tearing instability becomes worse for longer crack jumps in this case.

\section{REFERENCES}

[1] Structual Design Manual for Naval Surface Ships, NAVSEA 0900-LP-097-4010, Naval Ship Engineering Center, Dept. of Navy, Washington, DC 20362, Dec. 1976.

[2] Fracture-Control Guidelines for Welded Steel Ship Hulls, Ship Structures Committee, SSC-244, U.S. Coast Guard HQ, Washington, DC, 1974.

[3] R. B. King, T. Teramoto, D. T. Read, "Second Interim Progress Report: Materials Selection Criteria for Crack Arrester Strakes in Naval Vessels," NBSIR 84-3012, Oct. 1984.

[4] H. A. Ernst, "Some Salient Features of the Tearing Instability Theory," Elastic-Plastic Fracture: Second Symposium, Volume II-Fracture Resistance Curves and Engineering Applications, ASTM STP 803, C. F. Shih and J. P. Gudas, eds., ASTM, Philadelphia, PA, 1981, pp. 133-155.

[5] S. Kaiser, A. J. Carlsson, "Studies of Different Criteria for Crack Growth Instability in Ductile Materials," Elastic-Plastic Fracture: Second Symposium, Volume II-Fracture Resistance Cruves and Engineering Applications, ASTM STP 803, C. F. Shih and J. P. Gudas, eds., ASTM, Philadelphia, PA, 1981, pp. 58-79.

[6] P. C. Paris, H. Tada, A. Zahoor, H. Ernst, "The Theory of Instability of the Tearing Mode of Elastic-Plastic Crack Growth," 
Elastic-Plastic Fracture ASTM STP 668, J. D. Landes, J. A. Begley, G. A. Clarke, eds., ASTM, Philadelphia, PA, pp. 5-36.

[7] J.R. Rice, P. C. Paris, J. G. Merkle, "Some Further Results of J-Integral Analysis and Estimates," Progress in Flaw Growth and Fracture Toughness Testing, ASTM STP 536, ASTM, Philadelphia, PA.

[8] D. Broek, Elementary Engineering Fracture Mechanics, Martinus Nijhoff, The Hague, Boston, 1982.

[9] M. G. Vasilaros, J. P. Gudas, J. A. Joyce, "Experimental Evaluation of Tearing Instability Phenomena for Structural Materials," Rep. No. NUREG/CR-2570, U.S. Nuc. Reg. Comm., Washington, DC 1982.

[10] T. Teramoto, D. T. Read, R. B. King, "Fracture Mechanics Parameters in Crack Arrest Specimens," National Bureau of Standards, Boulder, CO (in review process). 


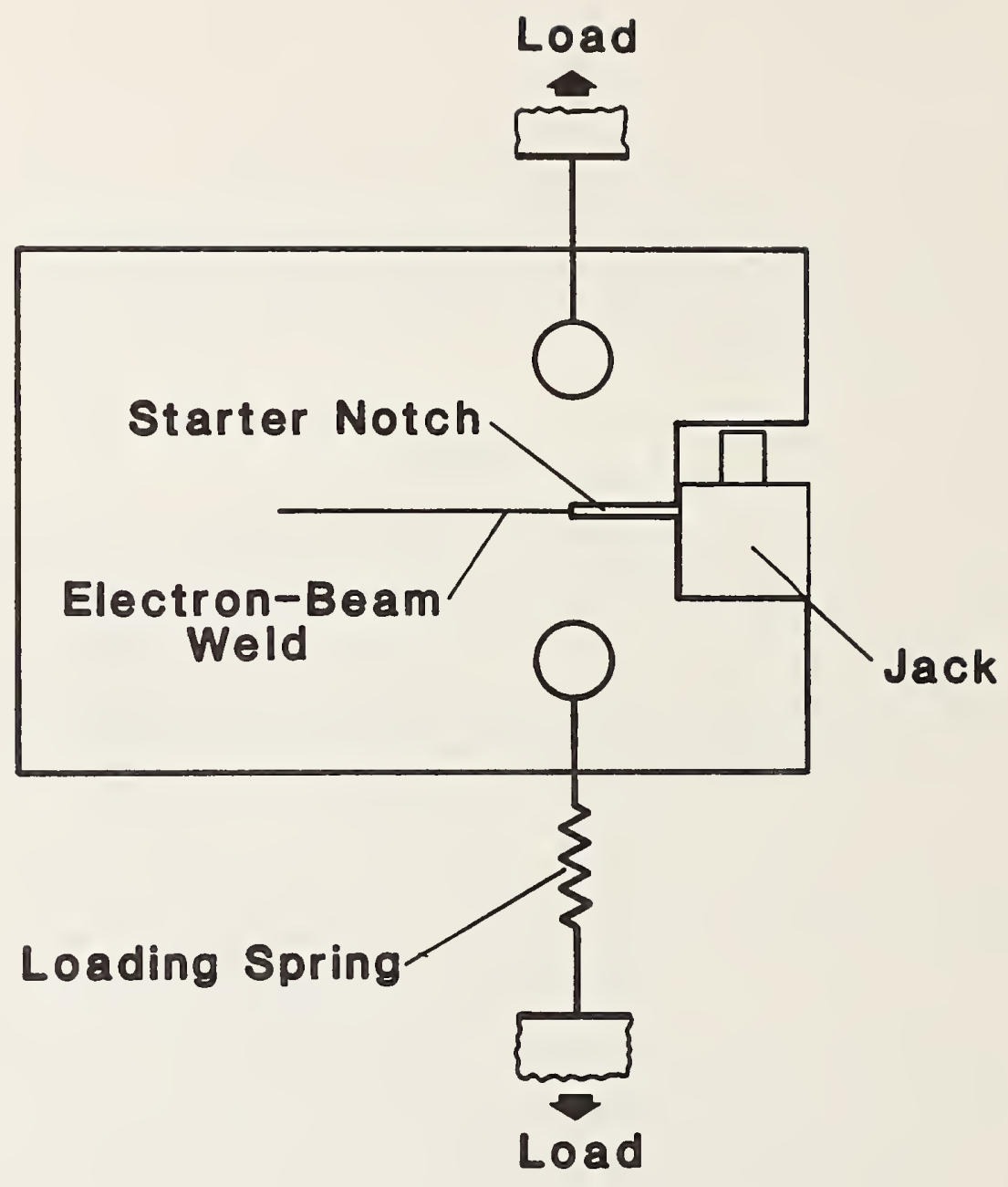

Modified double-cantilever beam (DCB) specimen used in NBS tests.

Figure 1 


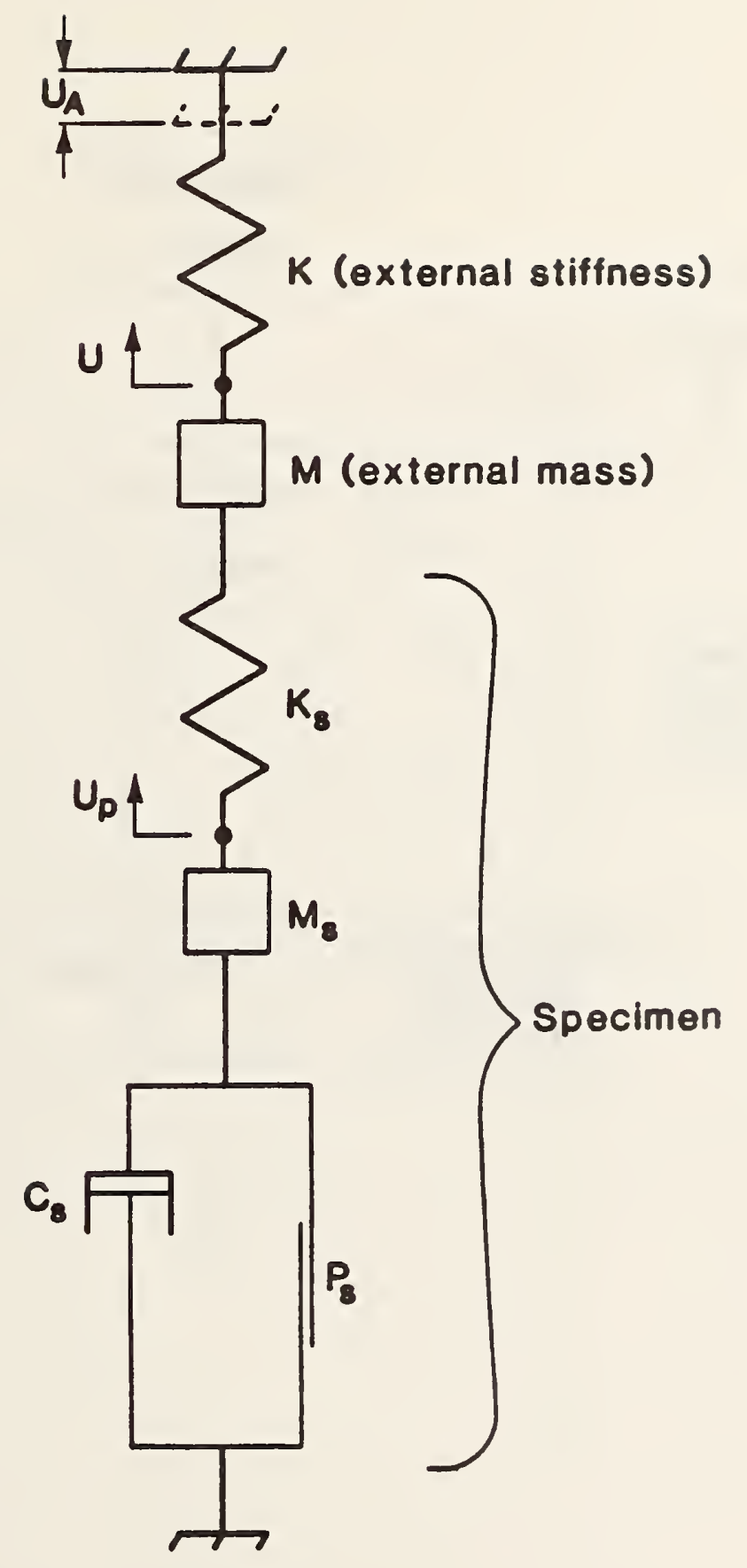

Lumped-mass viscoelastic-plastic dynamic model of DCB specimen.

Figure 2 


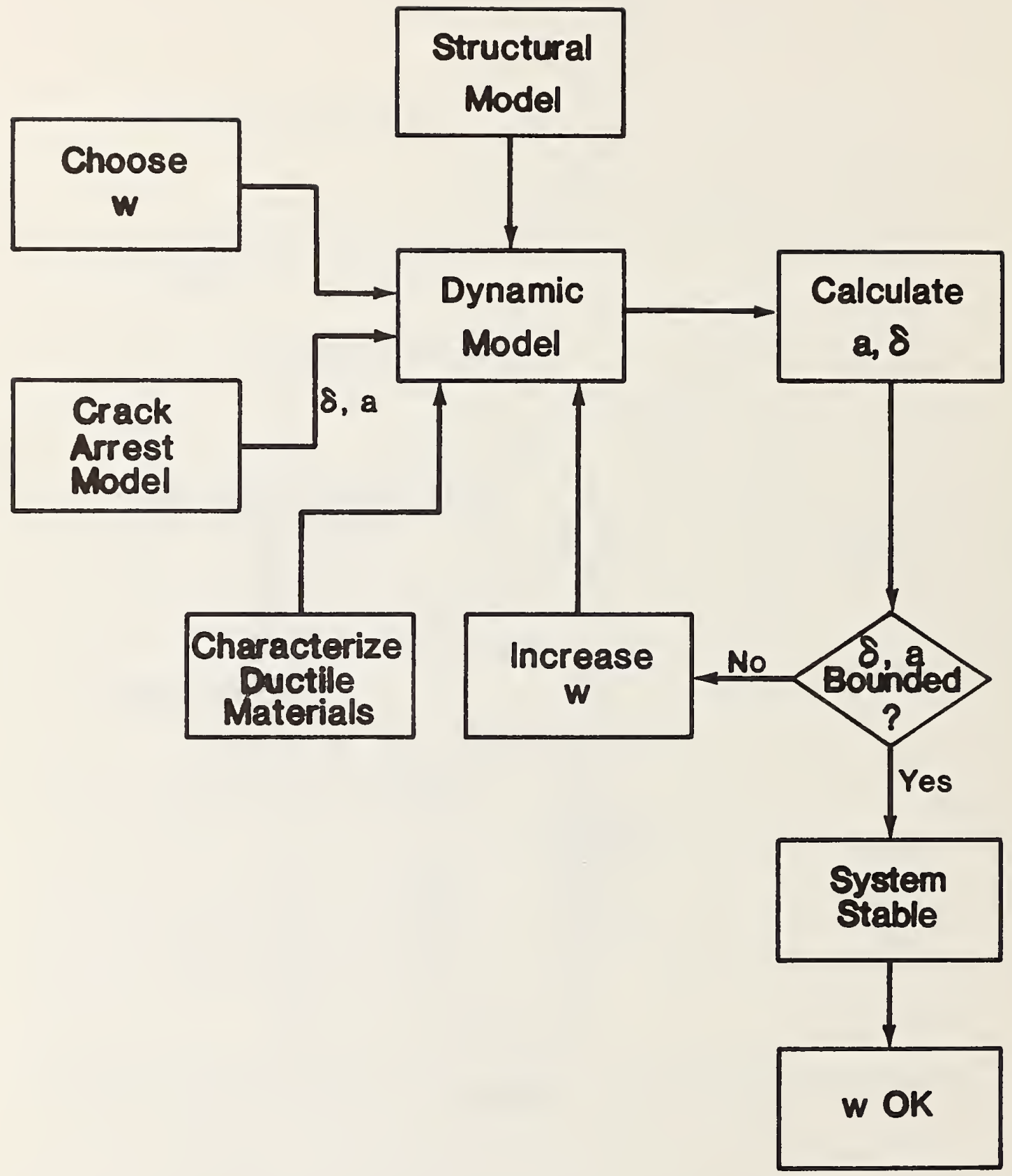

Flow chart for crack arrester design procedure.

Figure 3 


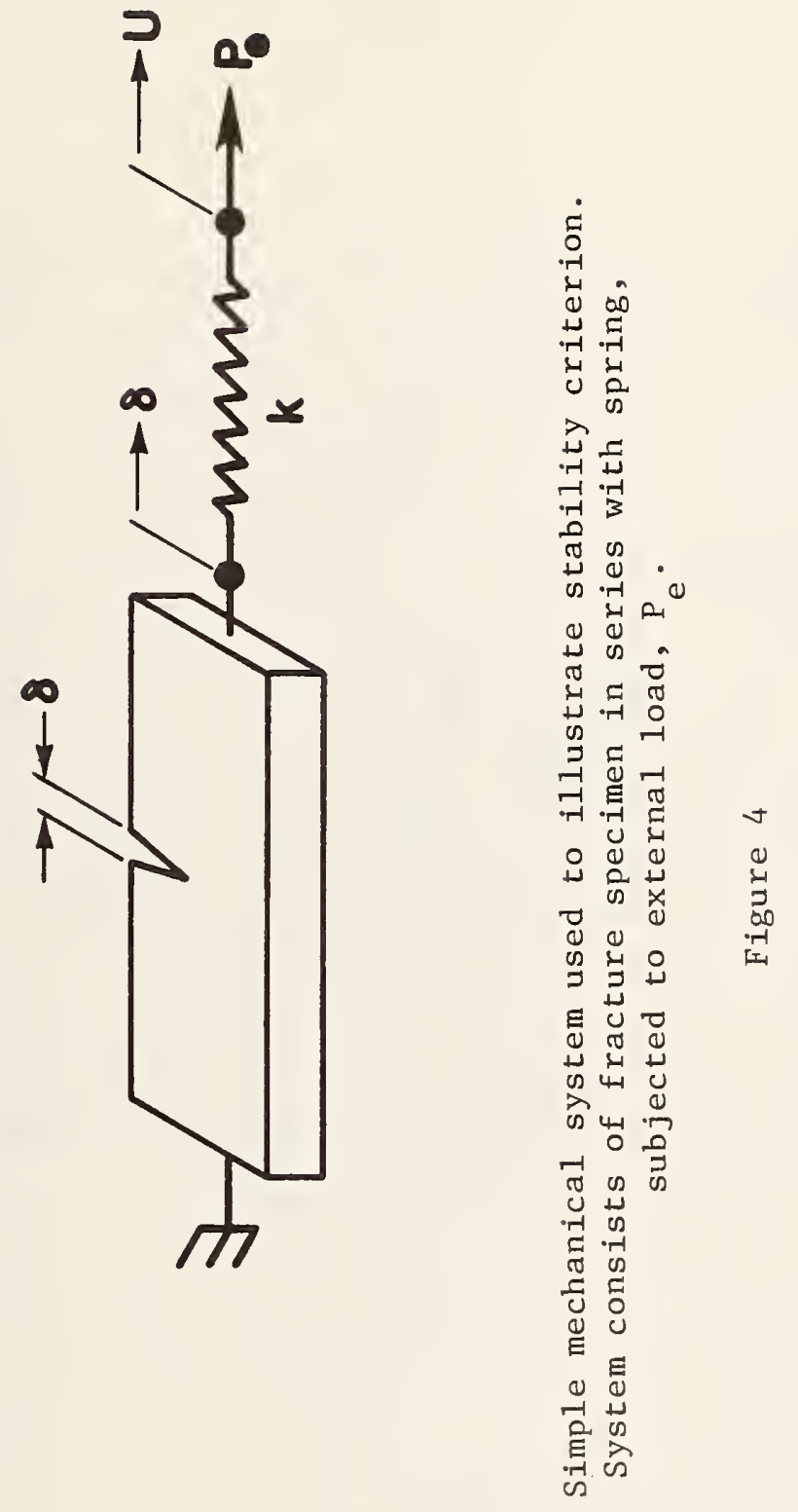



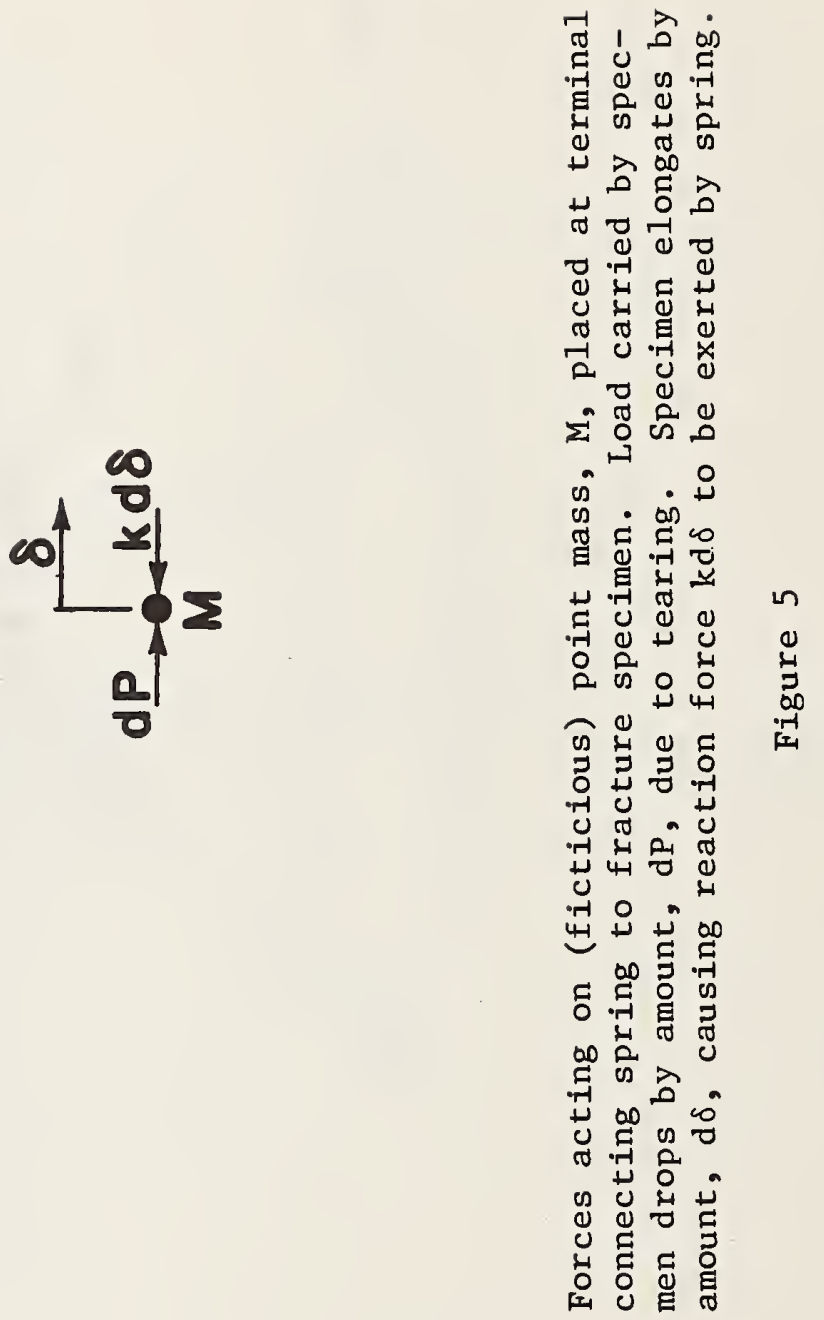



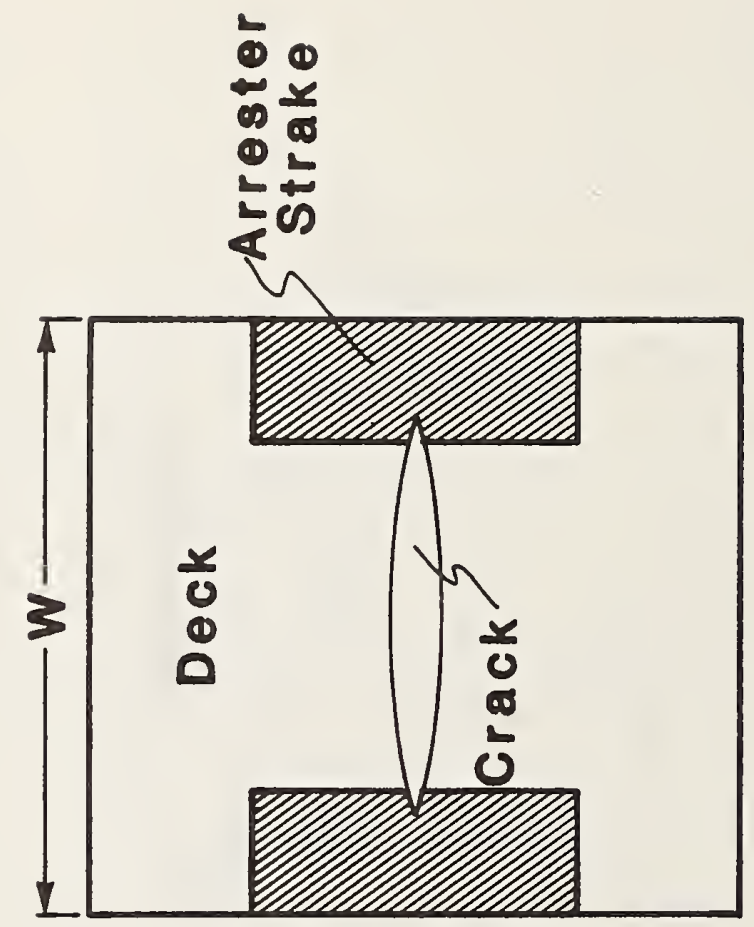

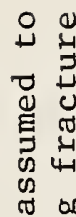

๘

की

㐘年

品的

.

Uै

용 용

पै प्रु

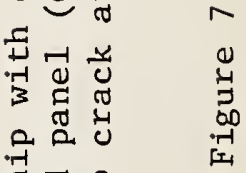

공

出苍苛

i o

वै क्षे

㟧艺

- 仓

స

瓷

릉 웅

荘 

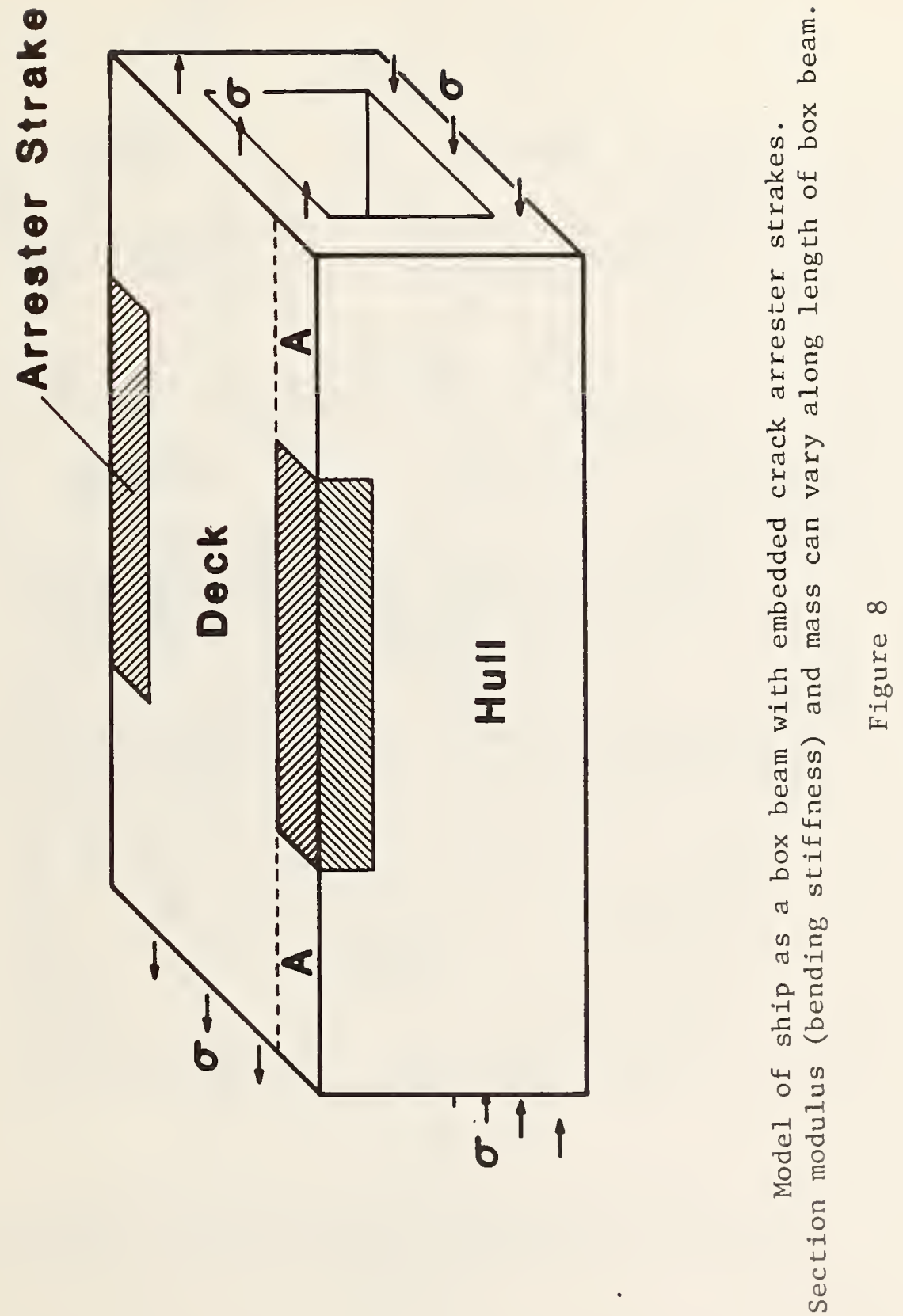

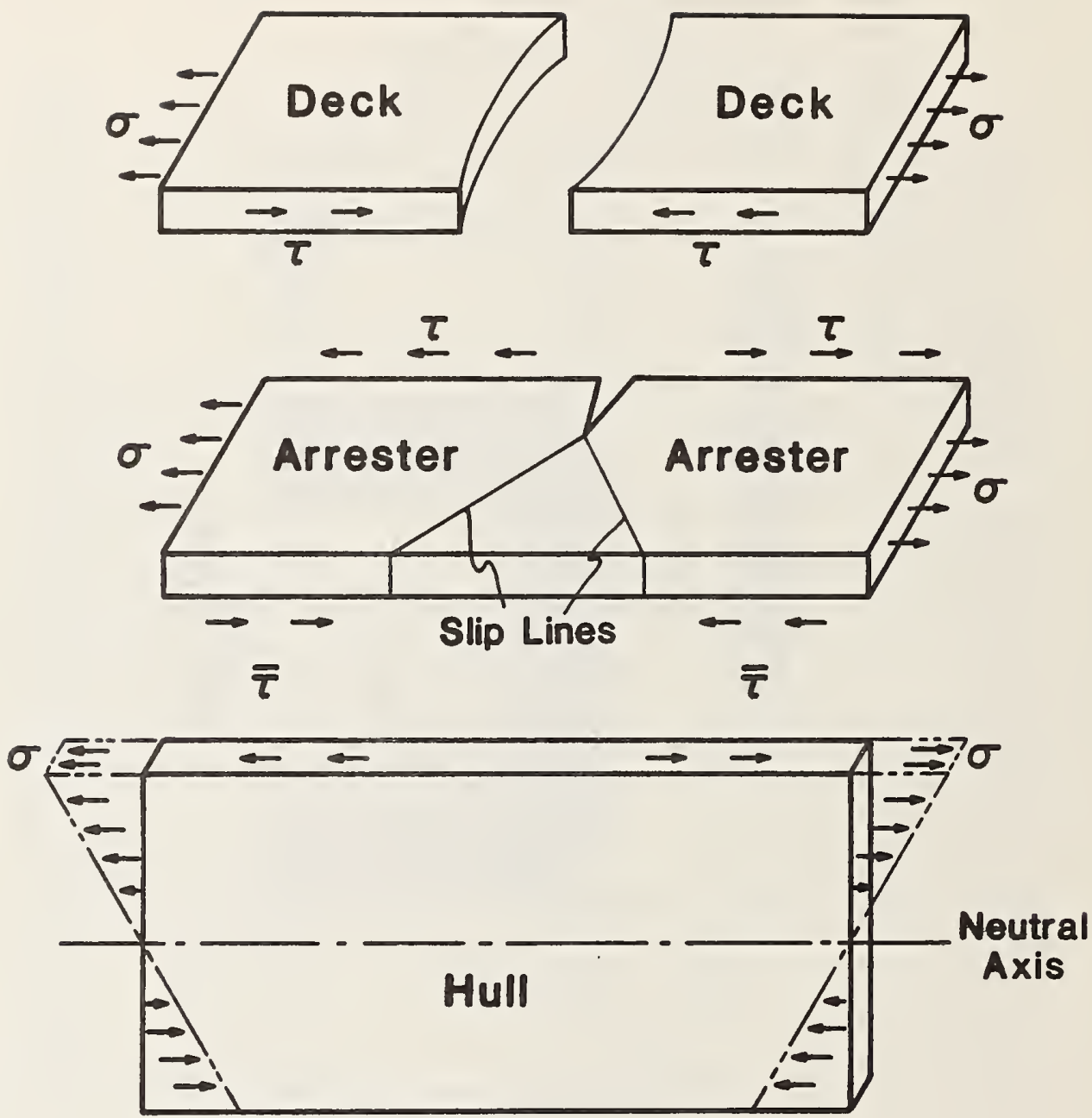

Exploded view of ship structure showing interaction stresses between structural components.

Figure 9 


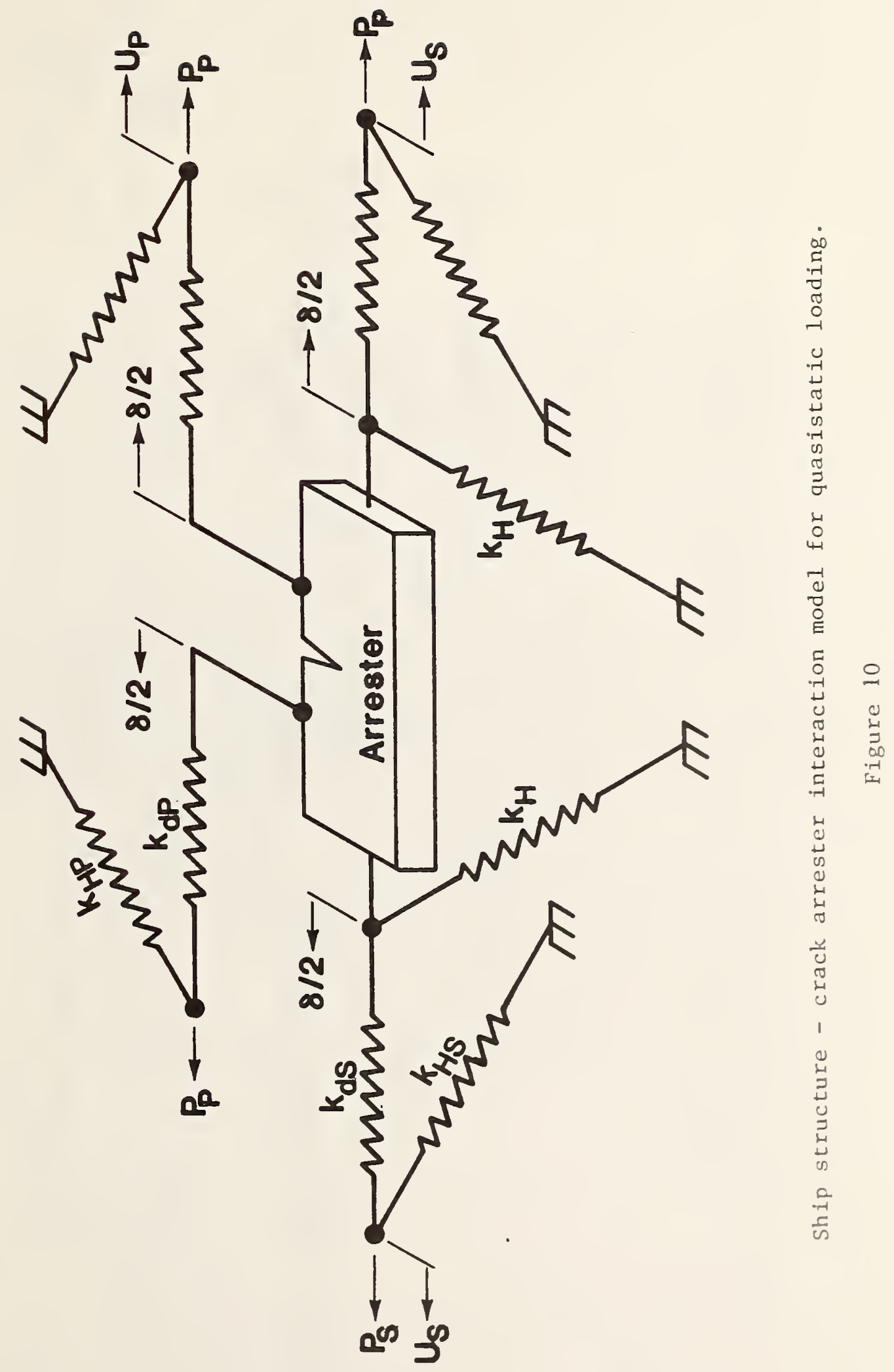




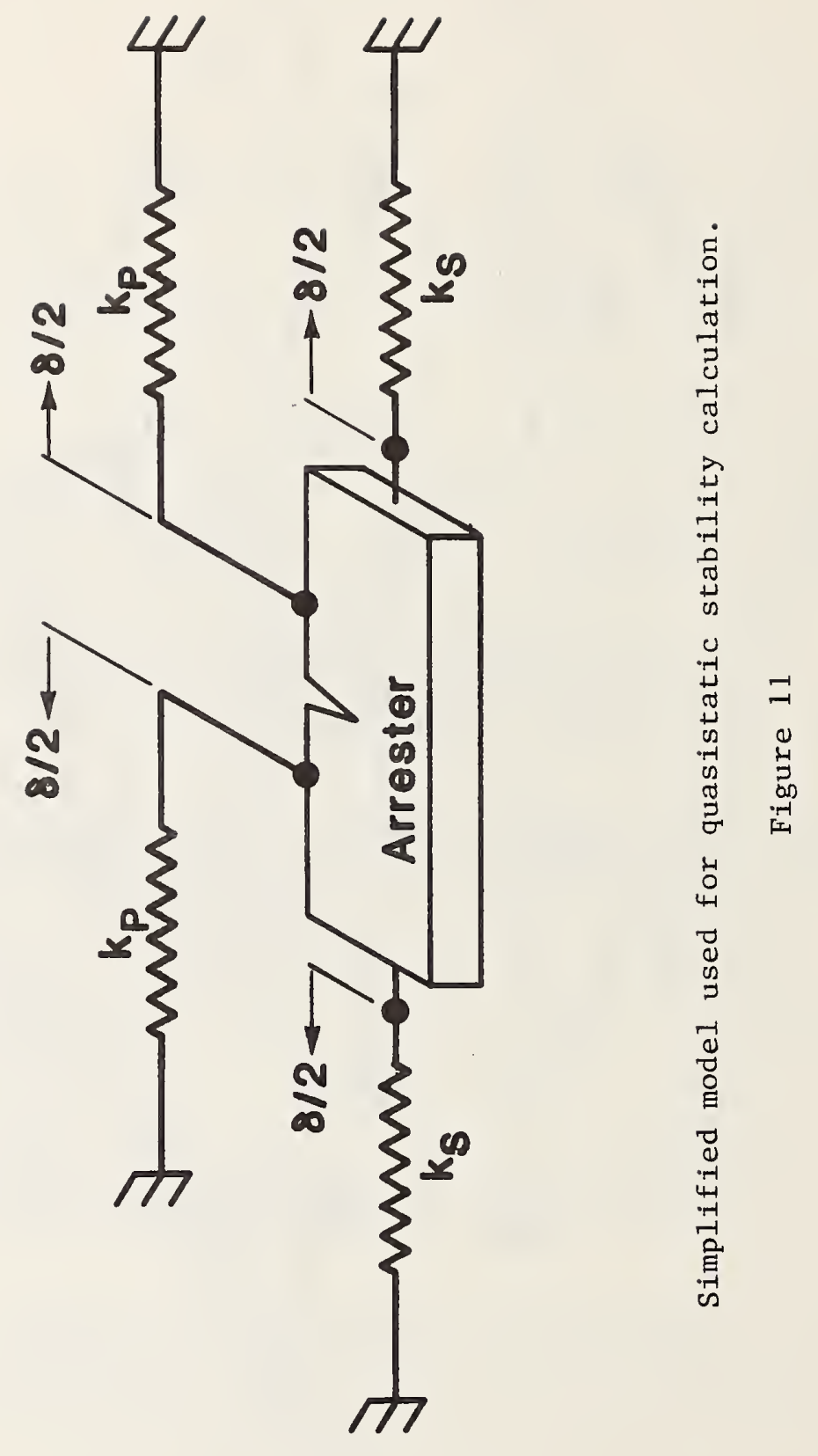




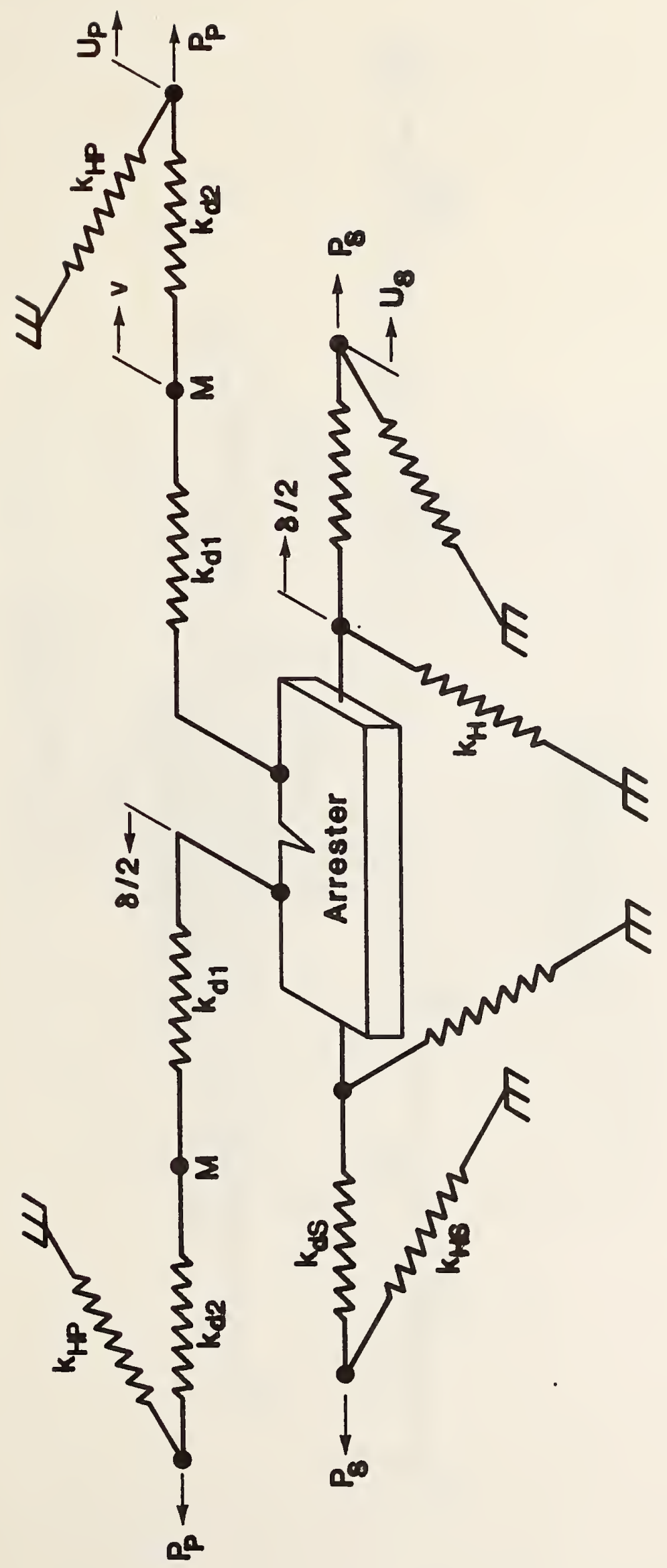




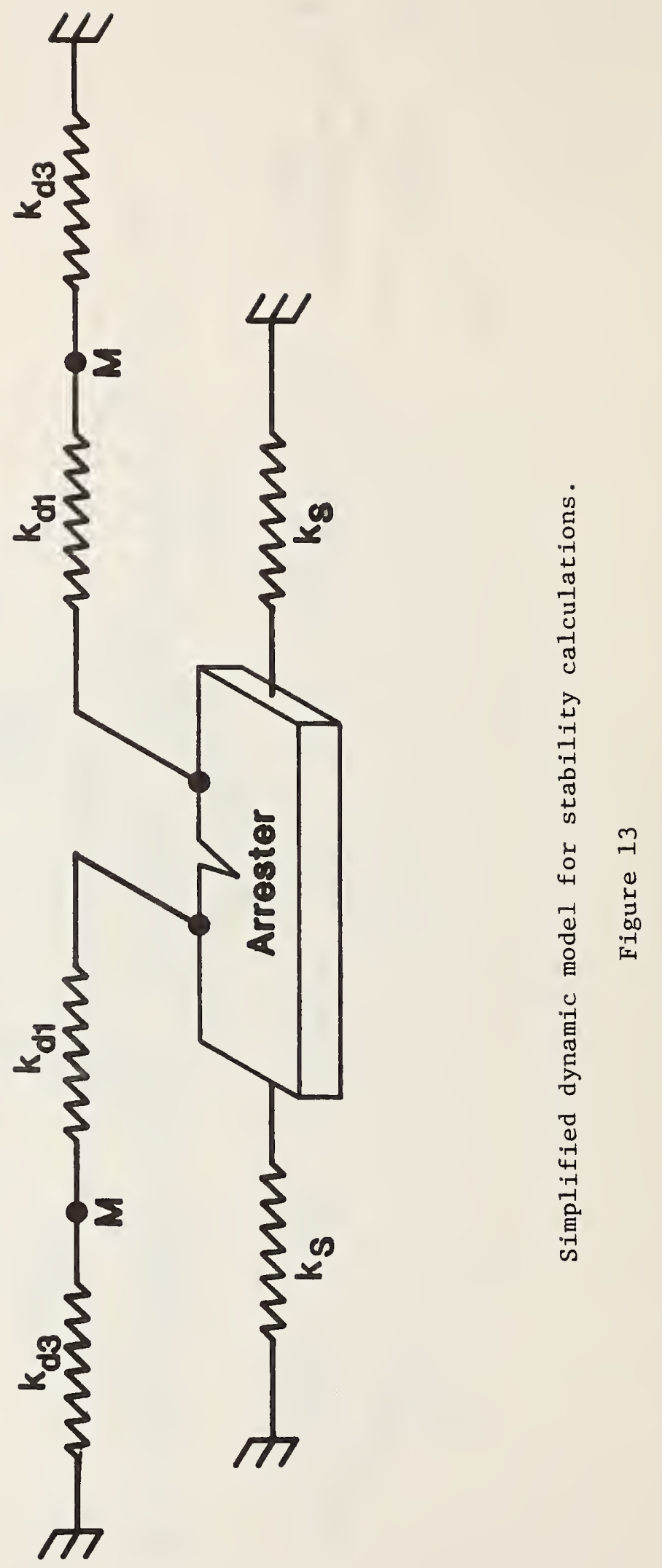




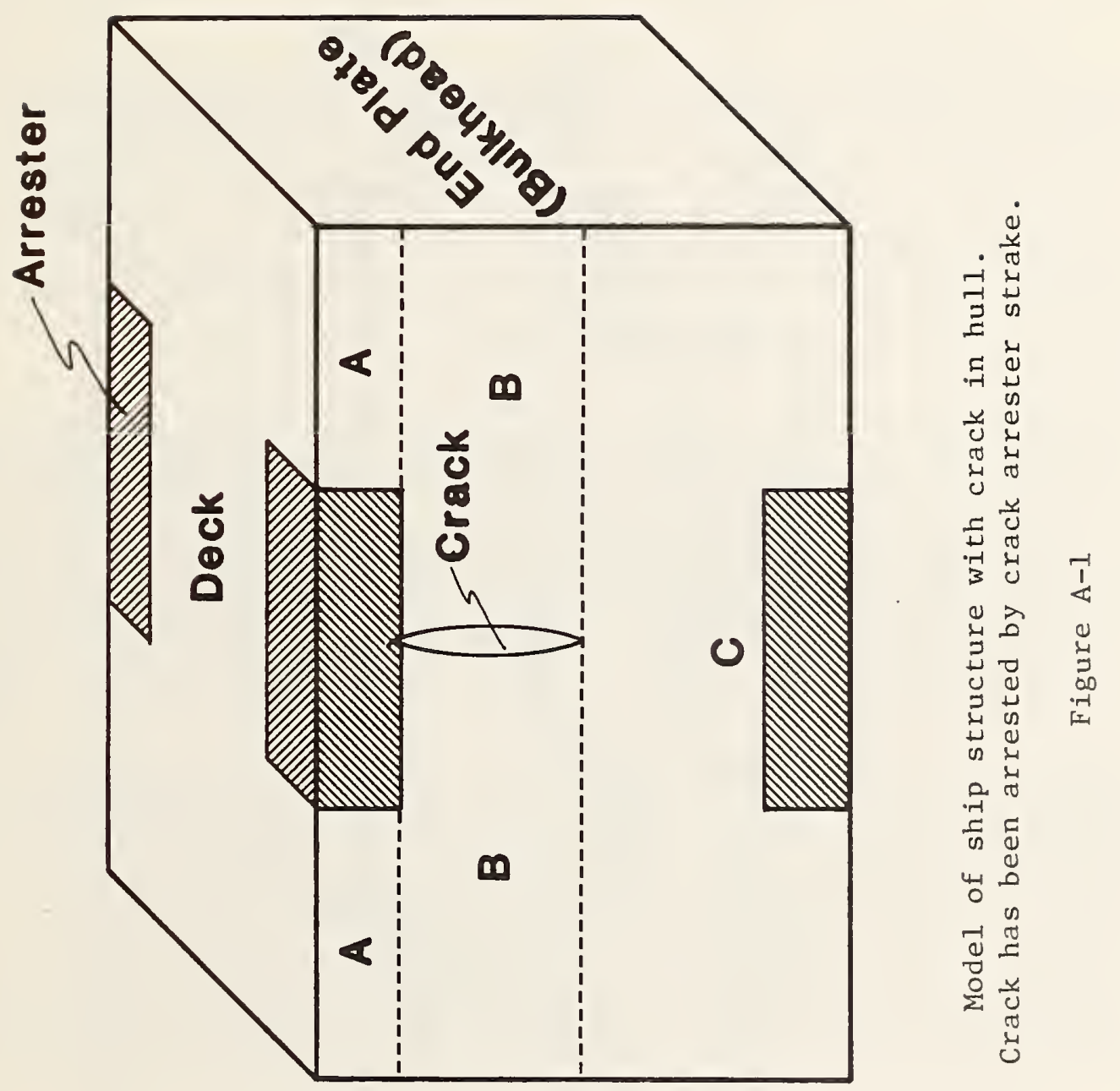




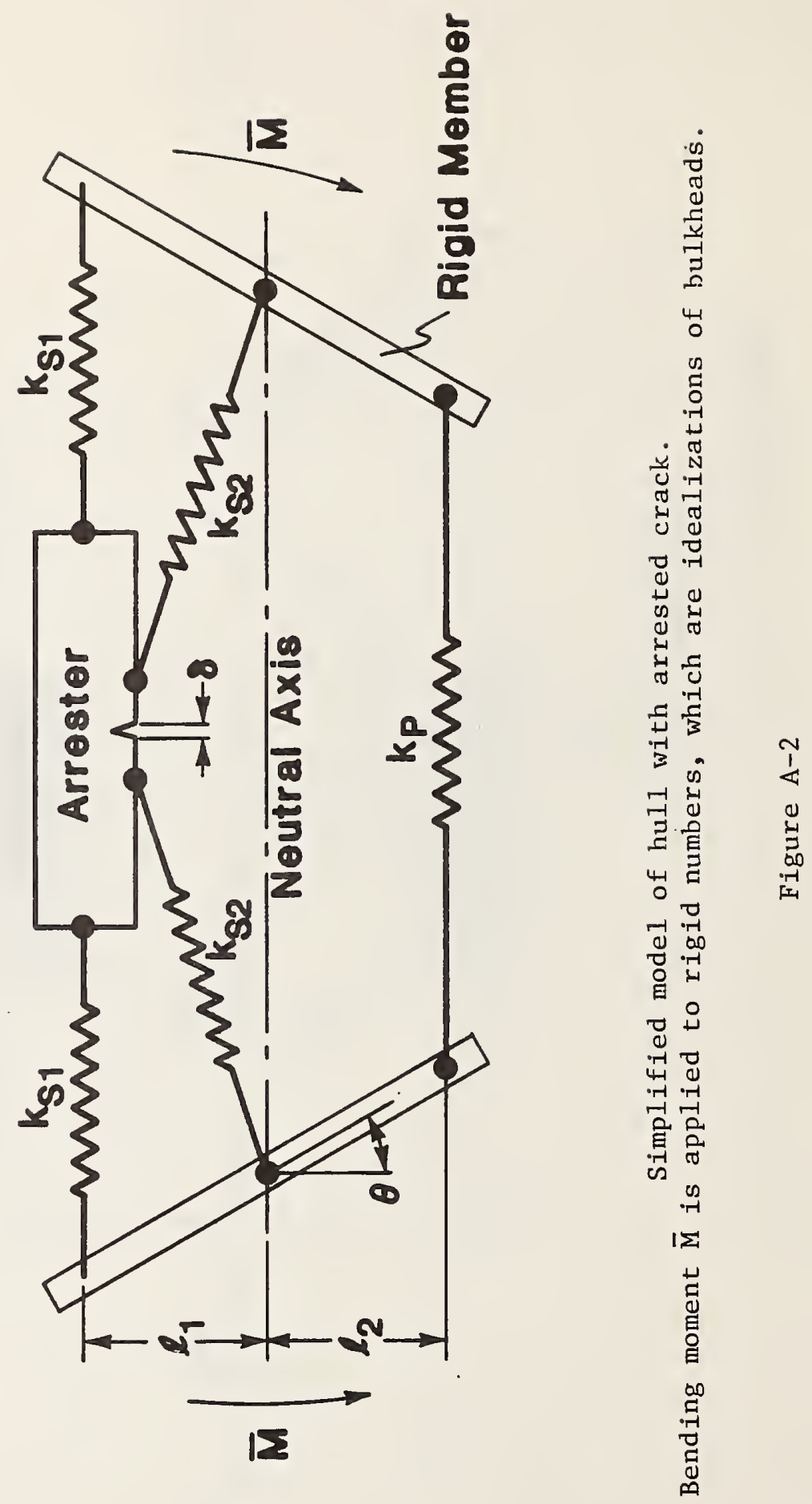


U.S. DEPT. OF COMM.

BIBLIOGRAPHIC DATA

SHEET (See instructions)
1. PUBLICATION OR
REPORT NO.
NBSIR $85-3038$

2. Performing Organ. Report No.

3. Publication Date

January 1986

4. TITLE AND SUBTITLE

Ductile Tearing Stability Analysis of a Ship Structure Containing a Crack Arrester Strake

5. $A \cup T H O R(S)$

A. V. Clark, Jr., and D. T. Read

6. PERFORMING ORGANIZATION (If joint or other than NBS, see instructions)

7. Contract/Grant No.

NATIONAL BUREAU OF STANDARDS

DEPARTMENT OF COMMERCE

WASHINGTON, D.C. 20234

8. Type of Report \& Period Covered Final Report

Sept.' '84 to Sept.' 85

9. SPONSORING ORGANIZATHON NAME AND COMPLETE ADCRESS (Street, City, Stote, ZIF)

David Taylor Naval Ship R \& D Center

Annapolis, Maryland

10. SUPPLEMENTARY NOTES

[ Document describes a computer program; SF-185, FIPS Software Summary, is attached.

11. ABSTRACT (A 200-word or less factual summary of most significant information. If document includes a significant bibliography or literature survey, mention it here)

An analysis is presented for a structure made up of a crack arrester plate embedded in a ship structure. The crack arrester material is specified by its crack arrest temperature, its strength, and its tearing modulus $T$ The remainder of the structure is characterized as a set of springs and lumped masses.

A stability condition is derived which states that the load-displacement curve of the structure as a whole must increase monotonically. An approximate quasistatic stability criterion sets a minimum material tearing modulus value that depends on the structural stiffness. Higher stiffness promotes effective crack arrest. A calculation including dynamic effects requires forward integration of a set of differential equations describing the fracture process and the motion of the structure. Repeating such a calculation for different values of crack arrester widths could indicate the minimum width needed for a successful (stable) crack arrest.

12. KEY WORDS (Six to twelve entries; alphabetical order; capitalize only proper names; ond separate key words by semicolons) arrester strakes; crack arresters; ductile fracture; ductile tearing instability; structural instability

\section{AVAILABILITY}

Unlimited

For Official Distribution. Do Not Release to NTIS

$\square$ Order From Superintendent of Documents, U.S. Government Printing Office, Washington, D.C. 20402.

14. NO. OF PRINTED PAGES

\section{4}

15. Price

Order From National Technical Information Service (NTIS), Springfield, VA。22161 


